\title{
Tropical Atlantic biases and their relation to surface wind stress and terrestrial precipitation
}

\author{
INGO RICHTER* \\ Research Institute for Global Change, JAMSTEC, Yokohama, Japan \\ and International Pacific Research Center, University of Hawaii at Manoa, Honolulu, Hawaii \\ SHANG-PING XIE \\ International Pacific Research Center and Department of Meteorology, University of Hawaii at Ma- \\ noa, Honolulu, Hawaii \\ ANDREW T. WITTENBERG \\ NOAA/Geophysical Fluid Dynamics Laboratory, Princeton, New Jersey \\ YUKIO MASUMOTO \\ Research Institute for Global Change, JAMSTEC, Yokohama, Japan
}

accepted in Climate Dynamics on February 21, 2011

Corresponding author:

Ingo Richter

Research Institute for Global Change, JAMSTEC

3173-25 Showa-machi, Kanazawa-ku, Yokohama

Tel.: +81-45-778-5523

Fax: +81-45-778-5707

E-mail: richter@jamstec.go.jp 


\begin{abstract}
Most coupled general circulation models (GCMs) perform poorly in the tropical Atlantic in terms of climatological seasonal cycle and interannual variability. The reasons for this poor performance are investigated in a suite of sensitivity experiments with the Geophysical Fluid Dynamics Laboratory (GFDL) coupled GCM. The experiments show that a significant portion of the equatorial SST biases in the model is due to weaker than observed equatorial easterlies during boreal spring. Due to these weak easterlies, the tilt of the equatorial thermocline is reduced, with shoaling in the west and deepening in the east. The erroneously deep thermocline in the east prevents cold tongue formation in the following season despite vigorous upwelling. The Bjerknes feedback further amplifies the SST biases and prolongs their effect in boreal summer when equatorial winds are close to observations.

It is further shown that the surface wind errors are due, in part, to deficient precipitation over equatorial South America and excessive precipitation over equatorial Africa, which already exist in the uncoupled atmospheric GCM. Additional tests indicate that the precipitation biases are highly sensitive to land surface conditions such as albedo and soil moisture. This suggests that improving the representation of land surface processes in GCMs offers a way of improving their performance in the tropical Atlantic.

The weaker than observed equatorial easterlies also contribute remotely, via equatorial and coastal Kelvin waves, to the severe warm SST biases along the southwest African coast. However, the strength of the subtropical anticyclone and along-shore winds also play an important role.
\end{abstract}




\section{Introduction}

The simulation of tropical Atlantic climate in coupled ocean-atmosphere general circulation models (GCMs) remains a challenging problem. Unlike in the Pacific basin, most models fail to simulate the observed cold tongue in the eastern equatorial Atlantic during June-July-August (JJA), resulting in a reversal of the equatorial zonal sea-surface temperature (SST) gradient in the annual mean (Davey et al. 2002). This problem continues to trouble state-of-the-art GCMs, as documented recently by Richter and Xie (2008; hereafter RX08), who showed that none of the models participating in the third Coupled Model Intercomparison Project (CMIP3) was able to reproduce the correct sign of the Atlantic equatorial SST gradient. It is not only at the equator, however, where GCMs experience serious difficulties. Severe warm biases also exist along the coasts of northwest and southwest Africa. In the subtropical South Atlantic, the warm coastal biases typically extend westward toward the center of the basin. In the subtropical North Atlantic, on the other hand, warm biases are rather confined to the coast while SSTs further west are cooler than observed.

The errors in the mean seasonal cycle of SST also affect the models' ability to simulate tropical Atlantic variability (TAV). This is particularly evident along the equator (Breugem et al. 2006) where the occurrence of interannual warm events (also termed Atlantic Niños) is anchored to the seasonal shoaling of the thermocline in boreal summer. Furthermore, errors in the mean state can affect ocean-atmosphere feedbacks and thus affect both the zonal and meridional modes of TAV (Xie and Carton 2004; Chang et al. 2006; Keenlyside and Latif 2007). As a result, current prediction models perform poorly in the region (Nobre and Repelli 2004; Stockdale et al. 2006; Huang et al. 2007). Since TAV is associated with pronounced precipitation anomalies on the adjacent continents that can affect the livelihoods of millions of people there is a dire need to improve the models' performance in the tropical Atlantic.

Several recent studies have investigated the causes for the persistent tropical Atlantic biases. Chang et al. (2007) found that SST biases in the Community Climate System Model version3 (CCSM3) are largely due to equatorial wind stress biases in MAM that originate in the atmospheric component. Independently, RX08 demonstrated that this pattern is robust across many GCMs. Comparing uncoupled atmospheric GCM (AGCM) simulations from the Atmospheric Model Intercomparison Project (AMIP) with their CMIP counterparts, RX08 find that, even when given "perfect SSTs", models produce a pronounced westerly bias over the equator during MAM. In coupled mode, this leads to a spurious deepening of the thermocline in the east that inhibits cold tongue formation in JJA. Such biases are further amplified by the Bjerknes feedback. The important role of equatorial wind stress is supported by Wahl et al. (2009) who perform a sensitivity test with the Kiel climate model in which they override wind stress from the atmospheric component with observed climatology over the equatorial Atlantic. However, since they prescribe wind stress year round, the particular importance of MAM surface winds needs further confirmation.

In addition to the wind stress bias in MAM, RX08 also find deficient and excessive precipitation over equatorial South America and Africa, respectively, consistent with an erroneously weak Atlantic Walker circulation. Since these terrestrial precipitation biases are robust across AMIP models, RX08 suggest that they might be one of the root causes 
of equatorial Atlantic biases. This is supported by a study of Chang et al. (2008) who were able to reproduce a substantial portion of the CAM3 westerly bias by forcing a primitive equation model with CAM3 heating anomalies over tropical South America.

A different source of equatorial Atlantic biases was proposed by Breugem et al. (2008), who suggest that spurious barrier layers (BLs) in the eastern equatorial Atlantic suppress vertical entrainment of sub-thermocline water into the mixed layer and thus lead to SST warming. One of the major mechanisms for the formation of BLs is freshwater flux associated with precipitation, which is directly linked to warm SST biases. This would suggest the existence of a positive feedback mechanism. However, excessive precipitation over the Congo basin might also contribute to spurious barrier layers via outflow from the Congo River mouth.

An issue that might be partly related to the equatorial deficiencies is the above mentioned warm SST bias in the southeastern subtropical Atlantic, which, along the coast, exceeds $5 \mathrm{~K}$ in many models. This bias exhibits comparatively little seasonal variability, in contrast to the JJA peak of the equatorial bias. Several model studies have attributed this error to excessive shortwave radiation associated with the under-representation of stratocumulus in GCMs (Large and Danabasoglu 2006; Huang et al. 2007; RX08; Wahl et al. 2009; Hu et al. 2010). If stratocumulus is the only reason, however, it remains unclear why the maximum SST error occurs just off the coast, given that observed stratus decks extend far offshore, and why SST and stratocumulus errors peak in different seasons.

The present study investigates factors leading to tropical Atlantic biases by addressing the following issues. 1) Can the crucial role of MAM wind stress biases be confirmed in the context of a coupled GCM? 2) To what extent are equatorial wind stress errors related to precipitation biases over South America and Africa? Are the precipitation biases sensitive to land surface conditions? 3) How important are BLs in the amplification of the warm bias in the eastern equatorial Atlantic? 4) Acknowledging the importance of stratus-related shortwave radiation in the southeastern Atlantic warm bias, are there any other important processes?

Our primary tool for addressing the above questions will be the GFDL GCM, which we briefly describe in section 2. Section 3 examines the link between equatorial SST biases and MAM wind stress, while section 4 examines how the MAM wind stress biases are, in turn, related to terrestrial precipitation biases. The role of spurious BLs in the eastern equatorial Atlantic cold tongue biases is tested in section 5. In section 6, we turn to the factors involved in southeast Atlantic SST biases. Conclusions are given in section 7.

\section{Model description and experiment design}

We use the GFDL coupled model version 2.1 (CM 2.1; Delworth et al. 2006) to test several hypotheses regarding tropical Atlantic biases (see Table 1 for a brief summary of experiments performed). The atmospheric component of the model is the GFDL AM 2.1, a finite volume AGCM with a resolution of $2.5^{\circ}$ longitude by $2^{\circ}$ latitude in the horizontal and 24 vertical levels (Delworth et al. 2006). The ocean component is based on the Modular Ocean Model version 4 (MOM4), a finite difference model with a horizontal resolution of $1^{\circ}$, with meridional grid spacing decreasing to $1 / 3^{\circ}$ toward the equator. The model has 50 vertical levels, with a spacing of $10 \mathrm{~m}$ in the top $220 \mathrm{~m}$ after which spacing gradually increases to about $500 \mathrm{~m}$ for the bottom layer. The model includes a land sur- 
face component (LM 2.1; GFDL Global Atmospheric Model Development Team, 2004) and a sea ice component (Delworth et al. 2006 and references therein). The four model components exchange fluxes using the Flexible Modeling System coupler, which passes atmospheric fluxes to the ocean every 2 hours. Further details of CM 2.1 and its performance can be found in Delworth et al. (2006) and Wittenberg et al. (2006).

The control simulation (CTRL hereafter) that serves as the reference for our experiments is a 300-year simulation with atmospheric composition, solar irradiance, and land cover held fixed at 1990 values. The simulation exhibits no significant trend in global temperatures over the integration period. Global surface temperature in CTRL is about $0.2 \mathrm{~K}$ warmer than that in the CM 2.1 run with historical 20th century forcing averaged over the period 1950-2000. This is about an order of magnitude smaller than the SST biases examined here and thus only slight exacerbates CM 2.1's Atlantic simulation. A 10year AGCM control simulation (CTRL_A) was also conducted to serve as a reference for AGCM sensitivity experiments in section 4 . The boundary conditions for this experiment are the same as for CTRL except that SSTs are specified from a monthly mean observational climatology.

Climatological mean fields of the coupled control simulation are contrasted with observations in Fig. 1. Both MAM and JJA feature the typical biases GCMs experience in the region (Figs. 1cd). MAM is characterized by a southward shift of the oceanic Intertropical Convergence Zone (ITCZ) with stronger than observed precipitation between the equator and $10^{\circ} \mathrm{S}$. This is accompanied by a northwesterly bias of surface winds between the equator and $8^{\circ} \mathrm{S}$. Terrestrial precipitation biases are marked by excessive precipitation over tropical Africa and a dipole pattern over South America with excessive precipitation south of the equator and deficient precipitation to the north of it. The most severe warm SST biases occur in the coastal upwelling regions of northwest and southwest Africa. In the latter case, these coastal biases extend far offshore, covering almost the entire subtropical South Atlantic. Much of the tropical North Atlantic features cold SST biases of up to $2 \mathrm{~K}$ associated with excessively strong northeast trades, reminiscent of the windevaporation-SST (WES) feedback (Xie and Carton 2004; Chang et al. 2006). In association with the southward gradient of the SST bias, the Intertropical Convergence Zone (ITCZ) is shifted southward during MAM. While equatorial surface zonal winds come into better agreement with observations during JJA, equatorial SST biases deteriorate. This is particularly evident in the eastern equatorial Atlantic where SSTs are up to $3 \mathrm{~K}$ warmer than observed.

The development of warm biases on the equator and along the southwest African coast is similar to interannual warm events in these regions, for which Kelvin waves play a role (Florenchi et al. 2003; Rouault et al. 2004; Luebecke et al. 2010). The warm bias off southwest Africa is associated with a weakened subtropical high over the South Atlantic in MAM (Fig. 1c), similar to the interannual warming associated with Benguela Niños (Polo et al. 2008; Lubbecke et al. 2010; Richter et al. 2010).

The erroneous surface winds during MAM have a clear impact on the oceanic circulation, as can be seen by comparing the simulated surface currents (Fig. 2a) with Atlantic Oceanographic and Meteorological Laboratory (AOML) drifter observations (Fig. 2c; Lumpkin and Garzoli 2005). The simulated equatorial currents are mostly eastward and thus reversed relative to observations. The Benguela current is also reversed while the Brazil current is weakened. These features are indicative of a weakened subtropical gyre. 
In JJA (Fig. 2b), the simulated SEC regains its westward direction and the subtropical gyre becomes anticyclonic again with a northward Benguela current. The magnitude of the SEC, however, is severely overestimated (Fig. 2f).

In the first set of sensitivity tests analyzed in section 3 we override the modelgenerated wind stress with observed monthly climatology over the equatorial Atlantic. These experiments are similar to the ones conducted by Wahl et al. (2009) with the important difference that overriding is performed during MAM only rather than year round. Furthermore, overriding is applied in a narrower zonal band with complete replacement only between $1^{\circ} \mathrm{S}$ and $1^{\circ} \mathrm{N}$ (as opposed to $4^{\circ} \mathrm{S}-4^{\circ} \mathrm{N}$ in Wahl et al. 2009). These modifications are designed to minimize intervention in the overall model dynamics while enabling substantial improvements in the simulated mean state of the tropical Atlantic. The wind stress modifications are only felt by the oceanic component, and only in terms of momentum exchange; sensible and latent heat flux calculations continue to be based on the model-generated near-surface winds. In order to avoid sharp gradients between the climatological and model-generated wind stress at the forcing boundaries $\left(1^{\circ} \mathrm{S}\right.$ and $\left.1^{\circ} \mathrm{N}\right)$, the model-generated wind stress is linearly blended in toward the poles, with $100 \%$ model-generated values poleward of $9^{\circ} \mathrm{S}$ and $9^{\circ} \mathrm{N}$. The blending is performed according to $\tau=\alpha \tau_{C}+\beta \tau_{M}$, where $\tau$ is the wind stress passed to the oceanic component, $\tau_{C}$ is wind stress from observed climatology, and $\tau_{M}$ is the wind stress generated by the atmospheric component. The blending coefficients are defined as $\alpha \equiv \frac{y_{0}-|y|}{y_{0}}$ for $1^{\circ} \leq|y| \leq y_{0}, \alpha \equiv 1$ for $|y|<1^{\circ}$ and $\alpha \equiv 0$ elsewhere, and $\beta \equiv 1-\alpha$. Here $y$ denotes latitude, and $y_{0} \equiv 9^{\circ}$.

In addition to the experiment described above (TAU_MAM hereafter) we performed a few more experiments to further confirm that it is indeed the MAM equatorial wind stress that is crucial in the generation of equatorial Atlantic biases. In TAU_JJA wind stress is overridden in the same region as in TAU_MAM but during JJA, while in TAU_ALL wind stress is overridden year round. Another experiment (TAU30) tests the potential impact of off-equatorial wind stress errors. In this experiment, overriding is performed year round and the region extended to $30^{\circ} \mathrm{S}-30^{\circ} \mathrm{N}$, with $y_{0} \equiv 40^{\circ}$.

In CTRL, the model generated wind stress is passed to the oceanic component every 2 hours. Replacing it with values interpolated from a monthly climatology eliminates high frequency variability, which can have an adverse effect on cold tongue development (e.g. Misra et al. 2008). Thus the improvements in our sensitivity tests might be greater if high frequency variability could be retained. However, given the severity of tropical Atlantic biases, this is likely to be a second order effect.

In a separate set of experiments we assess the role of tropical precipitation biases over South America and Africa that accompany the MAM wind stress errors. RX08 and Chang et al. (2008) suggest that terrestrial precipitation might be one of the key factors in the westerly wind stress bias over the equatorial Atlantic. In the present study we investigate to what extent terrestrial precipitation can influence surface wind patterns over the tropical Atlantic. To this end we induce precipitation anomalies by altering surface albedo and soil moisture in tropical South America and Africa. The changes in soil mois- 
ture are felt only by the atmosphere and have no direct influence on the land surface model.

The potential influence of spurious BLs is examined by performing an experiment that overrides surface fresh water fluxes over the tropical Atlantic region $\left(80^{\circ} \mathrm{W}-20^{\circ} \mathrm{E}\right.$, $30^{\circ} \mathrm{S}-30^{\circ} \mathrm{N}$ ) including land points. The purpose of this experiment is to eliminate erroneous fresh water fluxes into the eastern equatorial Atlantic and thus inhibit the formation of spurious BLs. Since these BLs might not be due to just local precipitation but also river run-off and horizontal advection (Breugem et al. 2008) we chose a fairly large modification area in this case.

Finally, we explore the southeast Atlantic SST bias and its relation to wind stress along the southwest African coast in an experiment that overrides wind stress in the Angola/Benguela area $\left(8^{\circ} \mathrm{E}-\right.$ coast, $\left.26^{\circ} \mathrm{S}-12^{\circ} \mathrm{S}\right)$ during MAM (TAU_ABA). Similarly to TAU_MAM, a small area is chosen to minimize interference with the model dynamics. Table 1 gives a summary of all the sensitivity experiments performed in this study.

Figure 3 illustrates for one particular sensitivity test, TAU_MAM, which was run for 20 years, how the model solution converges to a new equilibrium in response to the forcing. The figure plots the root-mean-square-error (RMSE) of equatorial Atlantic SSTs (average $2^{\circ} \mathrm{S}-2^{\circ} \mathrm{N}$ ) relative to the climatological mean of CTRL. The value for a particular year indicates the accumulated average of RMSE from the beginning of the simulation to that year. After year 10 of the sensitivity test, the accumulated average does not vary by more than $2 \%$. The rather rapid stabilization of the solution suggested by Fig. 3 motivated us to limit subsequent coupled sensitivity tests to 10 years (see Table 1). Uncoupled experiments are run for only 5 years. For each sensitivity experiment, climatological monthly means over the entire integration period are used to compare with CTRL and observations.

\section{Link between equatorial wind stress and SST biases}

\subsection{The influence of MAM wind stress}

Figures $4 \mathrm{c}$ and $\mathrm{d}$ show the model response to overriding equatorial wind stress with observed climatology during boreal spring only, as described in section 2. Even though wind stress errors are greatest during MAM (Fig. 1c), the model's SST response to the corrected wind stress during that season is only moderate (Fig. 4d), with equatorial cooling of about $1 \mathrm{~K}$, relative to CTRL. This is due to the fact that the mixed layer is deepest during boreal spring. Thus the intensified upwelling that results from prescribing observed wind stress has only a moderate impact on SSTs. Below the surface, however, the prescribed wind stress leads to a gradual shoaling of the eastern equatorial thermocline (as evidenced by the $20^{\circ} \mathrm{C}$ isotherm depth in Fig. 4) that persists into JJA when the forcing is switched off. Since JJA is the major upwelling season, the shoaled thermocline has a pronounced impact on eastern equatorial SSTs, resulting in a surface cooling of more than $2 \mathrm{~K}$ relative to CTRL (Fig. $4 \mathrm{~d}$ ). In the western equatorial Atlantic, on the other hand, the thermocline deepens in response to the prescribed wind stress, which leads to a warming of about $0.5 \mathrm{~K}$ there. The equatorial SST changes increase the zonal sea-level pres-

sure gradient (not shown), which in turn intensifies the equatorial easterlies. This Bjerknes type feedback helps to maintain a realistic thermocline tilt and thus prolongs the 
effect of the MAM forcing. It should also be noted that zonal temperature advection appears to play a role in the central equatorial Atlantic, where cooling occurs despite the deepened thermocline.

While SST improvements in the equatorial region are substantial, off-equatorial changes are moderate (Fig. 5). Perhaps most intriguing is the SST reduction of about $1 \mathrm{~K}$ that extends from the equator to $20^{\circ} \mathrm{S}$ along the southwest African coast in JJA (Fig. 5b). This is indicative of coastal thermocline adjustments in response to the altered MAM equatorial wind stress. Such remote influences from the equator are believed to play a role in the development of interannual warm events in the Angola/Benguela region (also named Benguela Niños) and several studies suggest that this influence is mediated via Kelvin waves (Florenchie et al. 2003; Polo et al. 2008, Lubbecke et al. 2010). This Kelvin wave mechanism might also be at work in the sensitivity experiment.

The subsurface structure of temperature and currents along the equator is shown as longitude-depth sections in Fig. 6. The wind stress forcing in TAU_MAM has a profound impact on the upper ocean circulation. This is particularly evident in the MAM nearsurface zonal current, which reverses its direction relative to CTRL and flows westward (Figs. 6a and c). The impact extends to the southeastern boundary where appreciable northward anomalies occur down to $15^{\circ} \mathrm{S}$, reversing the direction of the along-shore current (not shown). This latter aspect also contributes to the cooling along the southwest African coast discussed in the paragraph above.

The reversal of the equatorial current in MAM is accompanied by downwelling in the west and upwelling in the east thus reversing the sign of vertical velocity as well. The upwelling anomalies clearly increase the east-west tilt of the thermocline relative to CTRL where it is almost flat. As a consequence of the increased tilt, temperatures warm in the western half of the basin and cool in the eastern half (Fig. 6e), with the most pronounced anomalies located approximately at the depth of the thermocline. In JJA (Figs. $6 \mathrm{~b}, \mathrm{~d}$, and $\mathrm{f}$ ), the enhanced thermocline tilt and associated subsurface temperature changes persist but eastern equatorial upwelling is slightly weaker in TAU_MAM than in CTRL. This underlines that the pronounced JJA SST cooling (Fig.5b) in TAU_MAM is a result of the subsurface temperature anomalies rather than enhanced upwelling velocities.

While overriding MAM equatorial wind stress results in substantial improvements there clearly are limitations. This is particularly evident in the coastal regions of subtropical Africa (Figs. 5c and d) where the severe warm SST bias is only slightly alleviated. On the equator, SSTs remain too cool off the South American coast and too warm off the African coast (Fig. 4). Furthermore, the equatorial SST cooling in MAM slightly exacerbates the double ITCZ problem (Fig. 5c) by shifting precipitation southward.

To quantify the improvement in TAU_MAM we calculate the RMSE of equatorial Atlantic SSTs $\left(2^{\circ} \mathrm{S}-2^{\circ} \mathrm{N}\right)$ relative to observations (Table 2) for each month. Averaged over the entire year (JJA only), equatorial SSTs in TAU_MAM improve by $33 \%(42 \%)$ relative to CTRL.

The results so far have demonstrated that MAM equatorial wind stress leads to substantial changes in oceanic subsurface temperatures and currents along the equator, namely an increased east-west tilt of the thermocline and a reversal of the South Equatorial current, both of which bring the simulation into closer agreement with observations. While these changes develop in MAM, their clearest surface expression is found in the following JJA upwelling season. Though the wind stress forcing is only applied during 
MAM, oceanic inertia and the Bjerknes feedback help to prolong its beneficial effects through most of the year. All of these findings are in good agreement with the hypotheses put forward in RX08.

\subsection{Wind stress influence of other seasons and outside the equatorial region}

In order to test whether it is really the MAM equatorial wind stress that is crucial in eliminating equatorial SST biases, we performed three additional experiments. When equatorial wind stress is replaced in JJA instead of MAM (experiment TAU_JJA) improvements relative to CTRL are small (Fig. 7a) and limited to boreal summer. Averaged over the entire year, SST errors only slightly decrease as can be seen from Table 2. Furthermore, while equatorial SSTs in JJA cool by about $1 \mathrm{~K}$ relative to CTRL, this cooling has a rather uniform zonal structure and thus does little to improve the equatorial SST gradient. This result confirms that wind stress errors during JJA contribute little to the equatorial SST biases.

The potential influence of other seasons is tested in experiment TAU_ALL, in which equatorial wind stress is prescribed year round. Relative to TAU_MAM, the experiment features an additional decrease in eastern equatorial SST during JJA (Fig. 7b), while there are no significant improvements in other seasons (not shown). The improvements in JJA are confined to the eastern equatorial Atlantic, so that the overall RMSE improves by only $11 \%$ relative to TAU MAM (Table 2). The fact that TAU_ALL features significant improvements over TAU_MAM only during JJA suggests that CM 2.1's wind stress errors in SON and DJF have little influence on its equatorial SST biases.

Replacing model generated wind stress with observed climatology over the entire tropical Atlantic (experiment TAU30) yields further improvement, particularly in JJA (Fig. 7c). The overall improvement of RMSE is $54 \%$ relative to CTRL and $31 \%$ relative to TAU_MAM (Table 2). Away from the equator changes are modest and typically do not exceed $1 \mathrm{~K}$. An exception is the coastal zone off southwest Africa, where SSTs cool by up to $2 \mathrm{~K}$, which helps to reduce the warm bias in that region. This will be discussed further in section 6. In other parts of the southern Atlantic, SSTs mostly increase relative to TAU_MAM and thus exacerbate, albeit slightly, the warm SST bias in the region. This suggests that, for the southeast Atlantic warm bias, away from the African coast, wind induced latent heat flux errors play a larger role than the dynamical effects of wind stress errors. The impact of latent heat flux errors is also evident in Figs. $5 \mathrm{c}$ and d, where warm (cold) SST biases are accompanied by a weakening (strengthening) of the subtropical trade winds, indicative of the WES feedback.

We note that our results regarding TAU30 are somewhat different from those of Wahl et al. (2009) who found more substantial improvements in equatorial SST when they extended wind stress modifications to the subtropics. A possible explanation for the discrepancy is that off-equatorial wind stress errors might be larger in their model.

\subsection{The MAM wind-JJA SST relation and interannual variability in CTRL}

So far we have examined how artificial changes in the wind stress felt by the oceanic component affect the climatology of the model in terms of equatorial SST. These results have confirmed the relation between MAM surface winds and JJA SST posited by RX08. An alternative way of assessing this relation is to examine internal variability in the 
CTRL simulation. The GFDL model is well suited for this kind of analysis because it features significant year-to-year variability in both equatorial easterlies and SST. The result of the analysis is shown in Fig. 8, where each dot represents an individual model year in CTRL. The $\mathrm{x}$-axis indicates MAM zonal surface winds averaged over the central equatorial Atlantic $\left(35^{\circ} \mathrm{W}-25^{\circ} \mathrm{W}, 3^{\circ}-3^{\circ} \mathrm{N}\right)$, while the y-axis represents SST in the ATL3 region $\left(20^{\circ} \mathrm{W}-0,3^{\circ} \mathrm{S}-3^{\circ} \mathrm{N}\right)$. The figure is analogous to Fig. 7 of RX08 but here dots denote years rather than models.

The MAM zonal surface wind in CTRL ranges from -3 to $+3 \mathrm{~m} / \mathrm{s}$ (Fig. 8a), exceeding the variability of most other CMIP models. The JJA ATL3 is highly correlated with these variations with a correlation coefficient of 0.83 and an $R^{2}$ of 0.69 (when the equatorial SST gradient is used instead of ATL3 SST the correlation increases to 0.92). This underscores the crucial influence of MAM zonal surface winds on JJA SST in the equatorial Atlantic. However, is this close relation specific to CM 2.1 or robust across models? An intercomparison of CMIP 3 models (not shown) indicates that about one half of the models feature similarly high correlations while the other half has no significant correlation. All models with particularly severe warm SST biases belong to the latter group. In these models, both MAM wind and JJA SST variability is small. It is likely that if the thermocline depth in the eastern equatorial Atlantic exceeds a certain threshold, upwelling anomalies are rendered ineffective and coupled feedbacks shut off. However, some of the models that do not feature particularly severe SST biases still do not produce high correlations.

Comparing the climatologies of CMIP3 models, RX08 found a robust relation between MAM surface winds and JJA SST on the equator. The results presented here indicate that this relation does not necessarily hold for interannual variability in a given model. This however, does not conflict with the results of RX08 but rather suggests that interannual variability of JJA SST in the ATL3 can be influenced by other factors, one of them being the mean depth of the equatorial thermocline. Thus, in a model with a very deep thermocline, JJA SST will have a weak relation with MAM surface wind anomalies. In the climatological mean, however, JJA SST will still depend on the strength of the MAM equatorial easterlies because this is what controls the depth of the thermocline.

We have also examined the relationship between equatorial MAM zonal wind and JJA SST in the ERA40 reanalysis data (Fig. 8b). The observed correlation is rather weak, indicating that MAM wind is not the only determinant of Atlantic Niños in the subsequent season. This hints at a deficiency in the GCM simulations, possibly due to an excessively shallow thermocline in the central equatorial Atlantic. On the other hand, it is not clear how reliable reanalysis surface winds are. If the ERA40 results could be further substantiated with observations, the MAM-JJA relation could provide a new metric for evaluating GCM performance.

\section{Terrestrial influences on tropical Atlantic SST biases}

This section examines the model response to artificial modifications in the land surface conditions of tropical South America and Africa. The experiments are not designed to pinpoint specific land model deficiencies but rather to map out the model's sensitivity to land surface conditions. Specifically, we would like to examine whether surface albedo and soil moisture affect precipitation over tropical South America and Africa, and whether precipitation in these regions affects surface winds over the tropical Atlantic. If 
this is the case, it would indicate that improving land surface models has the potential to mitigate tropical Atlantic SST biases.

\subsection{South American influences}

In the first experiment, an AGCM-only experiment with SST prescribed from climatology, we set the MAM albedo of the Amazon rain forest to 0 . This is done by selecting all model grid cells in $\left(75^{\circ} \mathrm{W}-30^{\circ} \mathrm{W}, 15^{\circ} \mathrm{S}-10^{\circ} \mathrm{S}\right)$ whose land cover type is "tropical rainforest" and reducing their albedo by 0.15 . Linear tapering in time is performed to allow for a gradual onset (decay) of the anomalies during February (June). The experiment is designed to increase surface temperature and induce convection over the Amazon region. This does indeed occur as can be seen from Figure 9a, which shows an increase of MAM Amazon precipitation of about $3 \mathrm{~mm}$ /day relative to CTRL_A. Note, however, that most of this increase is located west and south of the observed precipitation maximum (Fig. 1a). Thus while the average amount of tropical South American rainfall is improved the pattern is not. This indicates a tendency of the simulated precipitation to be anchored to the location of the Andes.

In response to the increased Amazonian convection, the equatorial Atlantic easterlies increase by about $0.5 \mathrm{~m} / \mathrm{s}$ (Fig. 9a), suggesting a somewhat low sensitivity of surface winds to terrestrial precipitation. To quantify the improvements we calculate the area averaged MAM zonal surface wind speed over the equatorial Atlantic $\left(50^{\circ} \mathrm{W}-10^{\circ} \mathrm{E}, 2^{\circ}-\right.$ $2^{\circ} \mathrm{N}$ ). The values are $-2.5 \mathrm{~m} / \mathrm{s}$ for the ICOADS observations, $-1.5 \mathrm{~m} / \mathrm{s}$ for the AGCM control experiment, and -2.0 for the AMZN experiment. The same increase of surface easterlies also occurs in AMZN_C, the coupled counterpart to AMZN, where the equatorially averaged zonal surface wind is $-1.0 \mathrm{~m} / \mathrm{s}$ as compared to $-0.5 \mathrm{~m} / \mathrm{s}$ in CTRL (not shown). The JJA response to this intensification (Fig. 9b) is similar to the pattern seen in TAU_MAM, with SSTs slightly increasing in the western equatorial Atlantic and decreasing in the cold tongue region and southeastern Atlantic along the African coast. Due to the relatively small changes in surface winds, this SST response is about 7-8 times weaker than in TAU_MAM.

\subsection{African influences}

In this section we examine terrestrial influences from the eastern side of the Atlantic basin by artificially reducing precipitation and increasing surface pressure in the Congo basin. This is achieved by setting albedo to 0.5 (increasing the values in CTRL by approximately 0.3 ) and soil moisture to $200 \mathrm{~kg} / \mathrm{m}^{2}$ (increasing the values in CTRL by approximately $\left.150 \mathrm{~kg} / \mathrm{m}^{2}\right)$ in the area $\left(10^{\circ} \mathrm{E}-40^{\circ} \mathrm{E}, 5^{\circ} \mathrm{S}-5^{\circ} \mathrm{N}\right)$ during MAM. The albedo and soil moisture values prescribed correspond to those in desert and swamp regions, respectively. While artificially increasing soil moisture might seem counterproductive for decreasing precipitation, the associated evaporative cooling in the atmospheric boundary layer is very effective in amplifying the cooling that results from the increased albedo. The combined effect is an average surface temperature reduction of about $4 \mathrm{~K}$ in the Congo region, which essentially shuts down deep convection (Fig. 10a). This leads to a large-scale increase in surface pressure and an intensification of the MAM equatorial easterlies by about $2.5 \mathrm{~m} / \mathrm{s}$, so that they exceed the observed strength by about $0.5 \mathrm{~m} / \mathrm{s}$. 
The intensified MAM surface winds lead to improvements in the JJA SST gradient that are of similar magnitude as those in TAU_MAM (section 3).

It should be noted, however, that other aspects of the simulation deteriorate relative to CTRL. This includes a more pronounced double ITCZ (Fig. 10a) and SST warming along the northwest and southwest African coasts that exacerbates the pre-existing biases in these regions by about $3 \mathrm{~K}$ in JJA (Fig. 10b). The coastal warming appears to be linked to the decreased tropical convection over the eastern part of the basin, which leads to a weakening of the equatorward surface winds and thus reduces coastal upwelling.

\section{Barrier layer feedbacks}

This section investigates the potential role of barrier layers in Atlantic cold tongue biases. Breugem et al. (2008) suggest that erroneous barrier layers in the eastern equatorial Atlantic are caused by freshwater fluxes from excessive precipitation in the region. As excessive precipitation, in turn, is related to warm SST biases the argument becomes circular, indicating a coupled feedback loop. We test the potential role of this feedback in an experiment in which the model-generated freshwater flux is replaced with values derived from GPCP precipitation climatology over the tropical Atlantic $\left(30^{\circ} \mathrm{S}-30^{\circ} \mathrm{N}\right)$. In terms of eastern equatorial Atlantic SST, this leads to a slight increase (rather than a decrease) of SST by about $0.1 \mathrm{~K}$, which might not be significant. Following Breugem et al. (2008), we define the Atlantic cold tongue (ACT) index as the mean SST in the region $\left(10^{\circ} \mathrm{W}-10^{\circ} \mathrm{E}, 5^{\circ} \mathrm{S}-0^{\circ} \mathrm{N}\right)$. Figure 11 shows vertical profiles of potential temperature, potential density and salinity in the ACT region. In CTRL, both the pycnocline and the thermocline start at $15 \mathrm{~m}$ depth (the first three OGCM layers are centered at 5, 15, and $25 \mathrm{~m}$ ), with no indication of the temperature inversion (cool surface mixed layer overlying a warmer layer) that characterizes barrier layers (Breugem et al. 2008). Thus, already in CTRL, there is no indication of a barrier layer. This is also supported by the fact that, despite the warm and fresh biases, the vertical profiles of temperature and salinity are qualitatively similar to those in the World Ocean Atlas 2005 (WOA05; Locarnini et al. 2006) (not shown). In the sensitivity experiment, surface salinity increases by approximately 0.2 psu, reducing the salinity bias relative to WOA05 by $18 \%$. The difference between the sensitivity experiment and CTRL gradually diminishes with depth and is only $0.05 \mathrm{psu}$ at $100 \mathrm{~m}$. Temperature changes below the surface remain insignificantly small. Temperature changes in other tropical regions are also small and typically do not exceed $0.1 \mathrm{~K}$ (not shown). Thus results indicate that barrier layer feedbacks do not play a significant role in the tropical Atlantic biases of the GFDL model. Similar results were obtained in an independent study using the Community Climate System Model (Karthik Balaguru, personal communication).

\section{Southeast Atlantic biases}

Probably more persistent than the equatorial SST biases are those in the tropical southeastern Atlantic, and even GCMs that simulate the equatorial Atlantic rather realistically experience severe warm biases here (Stockdale et al. 2006; Huang et al. 2007; Wahl et al. 2009; Richter et al. 2010). Such deficiencies are also apparent in CTRL, where SSTs averaged between $8^{\circ} \mathrm{E}$ and the African coast are up to $6 \mathrm{~K}$ warmer than observed (Fig. 12a). Compared to the equator, SST biases in the southeast Atlantic show 
less seasonal variation, although they do tend to be more pronounced during boreal spring and early summer. This intensification might be related to the northerly wind biases along the African coast, which peaks about 2-3 months before the maximum SST bias. Many studies have also suggested that wind stress along the equator exerts a crucial influence on the coastal region of southwestern Africa via Kelvin waves for both interannual (Florenchie et al. 2004, Rouault et al. 2007, Lubbecke et al. 2010) and seasonal variability (Moore et al. 1978; Yamagata and Iizuka 1996).

We analyze how the southeastern Atlantic SST biases respond to both local and remote wind stress influences by re-examining two of the wind stress experiments in section 3 (TAU_ALL, TAU30) and by performing one additional experiment in which climatological wind stress is prescribed in the Angola/Benguela upwelling area (ABA), here defined as $\left(8^{\circ} \mathrm{E}-\right.$ coast, $\left.26^{\circ} \mathrm{S}-12^{\circ} \mathrm{S}\right)$. When equatorial wind stress is prescribed year round (TAU_ALL; Fig. 12b) boreal summer SSTs in the southeastern subtropical Atlantic cool by about $1.5 \mathrm{~K}$ relative to CTRL with the maximum response at $15^{\circ} \mathrm{S}$. Prescribing wind stress in the ABA only (TAU_ABA; Fig. 12d) leads to similar cooling of 1-1.5K between $15^{\circ}-25^{\circ} \mathrm{S}$, but further equatorward changes are small. These results suggest that, in the ABA, SST biases are due to both remote effects from the equator and deficiencies in local upwelling. Further equatorward, however, the equatorial influence is clearly dominant.

When wind stress is prescribed over the entire tropical Atlantic (TAU30; Fig. 12c), SSTs between the equator and $20^{\circ} \mathrm{S}$ cool by up to $4 \mathrm{~K}$ relative to CTRL, which exceeds the combined effect of the two previous experiments. The reason for the pronounced southeast Atlantic SST response in TAU30 becomes apparent when considering the upper ocean circulation averaged between 0-50m (Fig. 13). In CTRL (Fig. 13a), the direction of both the Brazil current and the Benguela current is opposite to observations, and even the equatorial current flows eastward in the eastern half of the basin. When the wind stress is corrected on the equator only (Fig. 13b) the equatorial current becomes westward but changes elsewhere in the basin are small. Correcting wind stress everywhere over the tropical Atlantic (Fig. 11c), on the other hand, induces northward anomalies in the Benguela current that cool SST along the southwestern African coast due to cold advection. Likewise, off the coast of Brazil, northward anomalies in the Brazil current warm ocean temperatures and reduce the cold bias in that region.

The experiments presented above demonstrate that basin wide improvements in surface winds are needed to achieve substantial bias improvement in the southeastern tropical Atlantic. This is evident from experiment TAU_ABA (Fig. 13d), in which temperature changes are relatively modest and confined to a narrow coastal band, even though there are some pronounced northward current anomalies along the southwest African coast between $15-25^{\circ} \mathrm{S}$.

\section{Summary and discussion}

Building on the results of Richter and Xie (2008) we have investigated some of the factors contributing to tropical Atlantic biases by means of sensitivity experiments with the GFDL GCM. In the first set of experiments (section 3) we have tested the link between equatorial MAM surface winds and JJA SST biases by substituting modelgenerated wind stress with observed climatology in various regions and seasons. About $1 / 3$ of the JJA equatorial bias is eliminated by overriding MAM equatorial wind stress only, which reduces cold tongue SSTs by $2.5 \mathrm{~K}$ and increases warm pool SST by $0.5 \mathrm{~K}$. 
Additional cooling of about $0.5 \mathrm{~K}$ in the cold tongue region is achieved when equatorial wind stress is overridden year round. Overriding wind stress over the whole tropics rather than just the equatorial region reduces the cold tongue bias a little more and also increases warm pool SSTs.

The JJA SST reduction in the above sensitivity experiments is due to the increased east-west tilt and eastern shoaling of the thermocline that develop in response to the strengthened MAM zonal wind stress. The Bjerknes feedback helps to maintain this increased thermocline tilt after the forcing is turned off.

Our results thus confirm that deficient easterly wind stress in MAM is the primary reason for the severe JJA equatorial SST biases in the GFDL coupled model. This is further supported by an analysis of internal interannual variability in the 300-year control simulation, which shows that equatorial MAM wind stress anomalies are highly correlated with JJA SST anomalies in the ATL3 region. Such a high correlation, however, is not found in the ERA 40 reanalysis, hinting at a potential model deficiency, e.g. an overly shallow thermocline. Alternatively, the low correlation in ERA 40 is due to insufficient observations to constrain fields over the equatorial Atlantic. If these uncertainties can be eliminated, the MAM winds - JJA SST relation could become an important measure for evaluating model performance.

The cause of the MAM westerly bias was examined in the second set of experiments, in which surface albedo and soil moisture were artificially modified to probe the sensitivity of equatorial surface winds to convection on the adjacent continents. Consistent with the hypothesis of Richter and Xie (2008) we find that increased convection over the Amazon rainforest and decreased convection over the Congo basin both act to strengthen, and thus improve, the equatorial MAM surface easterlies. These results, however, need to be qualified. First, while the land surface modifications are able to increase the average amount of South American precipitation, they fail to shift the precipitation center away from the Andes toward the observed location on the Atlantic coast. The tendency to produce maximum precipitation in vicinity of the Andes is a robust feature of CM 2.1 (and of most other IPCC AR4 models) as revealed by several other sensitivity tests not discussed here. Furthermore, reduced convection over the Congo basin and the attendant widespread increase in surface pressure, while strengthening equatorial easterlies, have the undesirable side-effect of weakening equatorward winds in the southeast and northeast Atlantic. In the coupled context this leads to SST warming in those regions, exacerbating pre-existing biases. Last, it should be noted that the artificial changes in surface conditions were highly idealized and thus do not offer a way to improve model performance. Rather, we have confirmed that changes in terrestrial precipitation do have the capacity to significantly improve tropical Atlantic simulations. The root causes for unrealistic convection over tropical South America and Africa might lie in the representation of land surface processes or in convection scheme deficiencies but further studies are needed to resolve these issues.

The role of spurious BLs in Atlantic cold tongue biases was tested in an experiment in which surface fresh water fluxes were prescribed from climatology. In contrast to the models examined by Breugem et al. (2008) we find no evidence of a barrier layer in the control simulation, although salinity biases certainly exist. When climatological fresh water fluxes are prescribed, salinity biases in the cold tongue region decrease but SST (as well as subsurface temperatures) remain almost unchanged. We therefore find no evi- 
dence of the coupled SST-precipitation-BL feedback suggested by Breugem et al. (2008). This response, however, might be specific to CM 2.1. BL feedbacks might still be important in some models that do feature spurious barrier layers in the region.

In the last part of this study, we have investigated the origin of southeast Atlantic SST biases near the coast of southern Africa. Our sensitivity experiments suggest that errors in both zonal equatorial winds and off-equatorial along-shore winds contribute to the warm SST biases. The most profound improvements, however, occur when climatological wind stress is prescribed over the entire tropical Atlantic. It thus appears that a basin-scale improvement of the subtropical anticyclone is needed to strengthen the gyre circulation and, in particular, to strengthen the northward Benguela current and coastal upwelling that help to cool waters in the tropical southeast Atlantic.

The present study has shown that land surface conditions in tropical South America and Africa exert a strong influence on local precipitation and tropical Atlantic climate. There is evidence pointing to systematic deficiencies in land surface schemes (e.g. Dirmeyer et al. 2006; Abramowitz et al. 2007). Evaluation of GCM performance over tropical rainforests is difficult because key variables such as soil moisture and surface temperature cannot be observed from space due to dense vegetation cover. Comparison studies thus have to rely mostly on in-situ data from a limited number of measurement sites. Nevertheless, there have been efforts to leverage existing satellite and in-situ observations to evaluate and improve model parameterizations (e.g. Wang et al. 2005; Pinty et al. 2006; Abramowitz et al. 2008). Further efforts along these lines will be necessary to achieve substantial improvements of GCM land surface parameterizations in the tropics.

Precipitation errors over tropical land surfaces can also be caused by unresolved subgrid-scale processes. Observations indicate that mesoscale convective systems (MCS) provide a significant portion of the precipitation over tropical South America and Africa (Yuan and Houze 2010). Studies suggest that subgrid-scale orography and terrain heterogeneity play an important role in initiating these MCSs (Kousky 1980; Laurent et al. 2002). Incorporating such effects into the convective parameterizations of GCMs will be another vital component for improving the performance of GCMs not only locally over tropical South America and Africa but the tropical Atlantic as well.

\section{Acknowledgments}

The authors would like to thank Dr. Swadhin Behera for his helpful comments. Thanks to the two anonymous reviewers for their helpful comments. This work was supported by the NOAA Climate Variability Program, NASA, and JAMSTEC. IPRC/SOEST publication \#xxx/yyy. 


\section{References}

Abramowitz G, Pitman A, Gupta H, Kowalczyk E, Wang Y (2007) Systematic bias in land surface models. J Hydrometeor 8:989-1001

Abramowitz G, Leuning R, Clark M, Pitman A (2008) Evaluating the performance of land surface models. J Clim 21:5468-5481

Breugem WP, Hazeleger W, Haarsma RJ (2006) Multimodel study of tropical Atlantic variability and change. Geophys Res Lett 33. doi:10.1029/2006GL027831

Breugem WP, Chang P, Jang CJ, Mignot J, Hazeleger W (2008) Barrier layers and tropical Atlantic SST biases in coupled GCMs. Tellus 60A:885-897.

Chang P, Coauthors (2006) Climate fluctuations of tropical coupled system - the role of ocean dynamics. J Clim 19:5122-5174

Chang CY, Carton JA, Grodsky SA, Nigam S (2007) Seasonal climate of the tropical Atlantic sector in the NCAR Community Climate System Model 3: error structure and probable causes of errors. J Clim 20:1053-1070

Chang CY, Nigam S, Carton JA (2008) Origin of the springtime westerly bias in equatorial Atlantic surface winds in the Community Atmosphere Model version 3 (CAM3) simulation. J Clim 21:4766-4778

Davey MK, Coauthors (2002) STOIC: A study of coupled model climatology and variability in tropical ocean regions. Clim Dyn 18:403-420

Delworth, T. L., Coauthors 2006: GFDL's CM2 global coupled climate models. Part I: Formulation and simulation characteristics. J. Climate, 19:643-674.

Dirmeyer PA, Koster RD, Guo Z (2006) Do global models properly represent the feedback between land and atmosphere? J Hydrometeor 7:1177-1198

GFDL Global Atmospheric Model Development Team (2004) The new GFDL global atmosphere and land model AM2/LM2: Evaluation with prescribed SST simulations. J Clim 17:4641-4673

Florenchie P, Lutjeharms JRE, Reason CJC, Masson S, Rouault M (2003) The source of Bengula Niños in the South Atlantic Ocean. Geophys Res Lett 30. doi:10.1029/2003GL017,172

Hu Z-Z, Huang B, Hou Y-T, Wang W, Yang F, Stan C, Schneider EK (2010) Sensitivity of tropical climate to low-level clouds in the NCEP climate forecast system. Clim Dyn doi 10.1007/s00382-010-0797-z.

Huang B, Hu Z-Z, Jha B (2007) Evolution of model systematic errors in the tropical Atlantic basin from coupled climate hindcasts. Clim Dyn 28:661-682

Keenlyside NS, Latif M (2007) Understanding equatorial Atlantic interannual variability. J Clim 20:131-142

Kousky VE (1980) Diurnal rainfall variation in northeast Brazil. Mon Weather Rev 108:488-498

Large WG, Danabasoglu G (2006) Attribution and impacts of upper-ocean biases in CCSM3. J Clim 19:2325-2346

Laurent H, Machado LAT, Morales CA, Durieux L (2002) Characteristics of the Amazonian mesoscale convective systems observed from satellite and radar during the WETAMC/LBA experiment. J Geophys Res 107 doi:10.1029/2001JD000337

Locarnini RA, Mishonov AV, Antonov JI, Boyer TP, Garcia HE (2006) World Ocean Atlas 2005, Volume 1: Temperature. S. Levitus, Ed. NOAA Atlas NESDIS 61, U.S. Government Printing Office, Washington, D.C., 182 pp 
Lubbecke JF, Boning CW, Keenlyside NS, Xie S-P (2010) On the connection between Benguela and equatorial Niños and the role of the South Atlantic anticyclone. J Geophys Res, doi:10.1029/2009JC005964, in press

Lumpkin R, Garzoli S (2005) Near-surface circulation in the Tropical Atlantic Ocean Deep-Sea Research I 52, 495-518, 10.1016/j.dsr.2004.09.001.

Misra V, Marx L, Brunke M, Zeng X (2008) The equatorial Pacific cold tongue bias in a coupled climate model. J Clim 21:5852-5869

Moore D, Hisard P, McCreary J, Merle J, O'Brien J, Picaut J, Verstraete J-M, Wunsch C (1978) Equatorial adjustment in the eastern Atlantic. Geophys Res Lett 5:637-640

Pinty B, Lavergne T, Dickinson RE, Widlowski J-L, Gobron N, Verstraete MM (2006) Simplifying the interaction of land surfaces with radiation for relating remote sensing products to climate models. J Geophys Res 111 doi:10.1029/2005JD005952

Polo I, Rodríguez-Fonseca B, Losada T, García-Serrano J (2008) Tropical Atlantic variability modes (1979-2002). Part I: time-evolving SST modes related to West African rainfall. J Clim 21:6457-6475

Repelli CA, Nobre P (2004) Statistical prediction of sea surface temperature over the tropical Atlantic. Int J Climatol, 24:45-55

Richter I, Xie S-P (2008) On the origin of equatorial Atlantic biases in coupled general circulation models. Clim Dyn 31:587-598

Richter I, Behera SK, Masumoto Y, Taguchi B, Komori N, Yamagata T (2010) On the triggering of Benguela Niños - remote equatorial vs. local influences. Geophys Res Lett 37. doi:10.1029/2010GL044461

Rouault M, Illig S, Bartholomae C, Reason CJC, Bentamy A (2007) Propagation and origin of warm anomalies in the Angola Benguela upwelling system in 2001. J Mar Systems 68:473-488

Stockdale TN, Balmaseda MA, Vidard A (2006) Tropical Atlantic SST prediction with coupled ocean-atmosphere GCMs. J Clim 19:6047-6061

Wahl S, Latif M, Park W, Keenlyside N (2009) On the Tropical Atlantic SST warm bias in the Kiel Climate Model. Clim Dyn, DOI 10.1007/s00382-009-0690-9

Wittenberg AT, Rosati A, Lau N-C, Ploshay JJ (2006) GFDL's CM2 global coupled climate models. Part III: Tropical Pacific climate and ENSO. J Clim 19:698-722

Xie S-P, Carton JA (2004) Tropical Atlantic variability: Patterns, mechanisms, and impacts. In Earth Climate: The Ocean-Atmosphere Interaction Geophysical Monograph, vol 147. AGU, Washington DC, pp 121-142Wang D, Wang G, Agnostou EN (2005) Use of satellite-based precipitation observation in improving the parameterization of canopy hydrological processes in land surface models. J Hydrometeor 6: 745-763

Yamagata T, lizuka S (1995) Simulation of the tropical thermal domes in the Atlantic: A seasonal cycle. J Phys Oceanogr 25:2129-2140

Yuan J, Houze Jr, A (2010) Global variability of mesoscale convective system anvil structure from A-train satellite data. J Clim 23:5864-5888 


A. Tables
\begin{tabular}{|c|c|c|}
\hline $\begin{array}{c}\text { experiment } \\
\text { name }\end{array}$ & $\begin{array}{c}\text { length of } \\
\text { simulation }(\mathrm{yr})\end{array}$ & description \\
\hline CTRL & 300 & CM 2.1 control simulation with 1990 radiative forcing \\
\hline CTRL_A & 10 & AGCM control simulation with 1990 radiative forcing \\
\hline TAU_MAM & 20 & MAM equatorial wind stress overridden with ICOADS \\
\hline TAU_JJA & 10 & JJA equatorial wind stress overridden with ICOADS \\
\hline TAU_ALL & 10 & equatorial wind stress overridden throughout the year \\
\hline TAU30 & 10 & $\begin{array}{c}\text { tropical Atlantic }\left(30^{\circ} \text { S-30 } 3 \text { N) wind stress overridden }\right. \\
\text { throughout the year }\end{array}$ \\
\hline TAU_ABA & 10 & ABA wind stress overridden throughout the year \\
\hline AMZN & 5 & Amazon albedo set to 0 in uncoupled AM 2.1 \\
\hline AMZN_C & 10 & coupled counterpart to AMZN \\
\hline CGO & 5 & Congo albedo set to 0.5, soil moisture to $200 \mathrm{~kg} / \mathrm{m}^{2}$ \\
\hline CGO_C & 10 & coupled counterpart to CGO \\
\hline FWFLUX & 10 & tropical Atlantic fresh water flux overridden with \\
& & GPCP \\
\hline
\end{tabular}

Table 1 Summary of GCM experiments performed for this study. Simulation length is given in years.

\begin{tabular}{|c|c|c|c|}
\hline experiment name & $\begin{array}{c}\text { SST RMSE (K) } \\
\text { (relative to obs) }\end{array}$ & $\begin{array}{c}\text { improvement (\%) } \\
\text { (relative to CTRL) }\end{array}$ & $\begin{array}{c}\text { improvement (\%) } \\
\text { (relative to TAU_MAM) }\end{array}$ \\
\hline CTRL & 1.29 & N/A & N/A \\
\hline TAU_MAM & 0.87 & 33 & N/A \\
\hline TAU_JJA & 1.25 & 3 & 11 \\
\hline TAU_ALL & 0.76 & 41 & 31 \\
\hline TAU30 & 0.60 & 54 & N/A \\
\hline TAU_ABA & 1.25 & 3 & \\
\hline
\end{tabular}

Table 2 Root-mean-square error (RMSE) of climatological SST relative to ICOADS observations for various sensitivity experiments. RMSE is calculated for equatorial Atlantic SST between $2^{\circ} \mathrm{S}-2^{\circ} \mathrm{N}$ and averaged over the entire year. The third column shows the RMSE improvement relative to CTRL, the fourth column the improvement relative to TAU_MAM. 


\section{B. Figures}
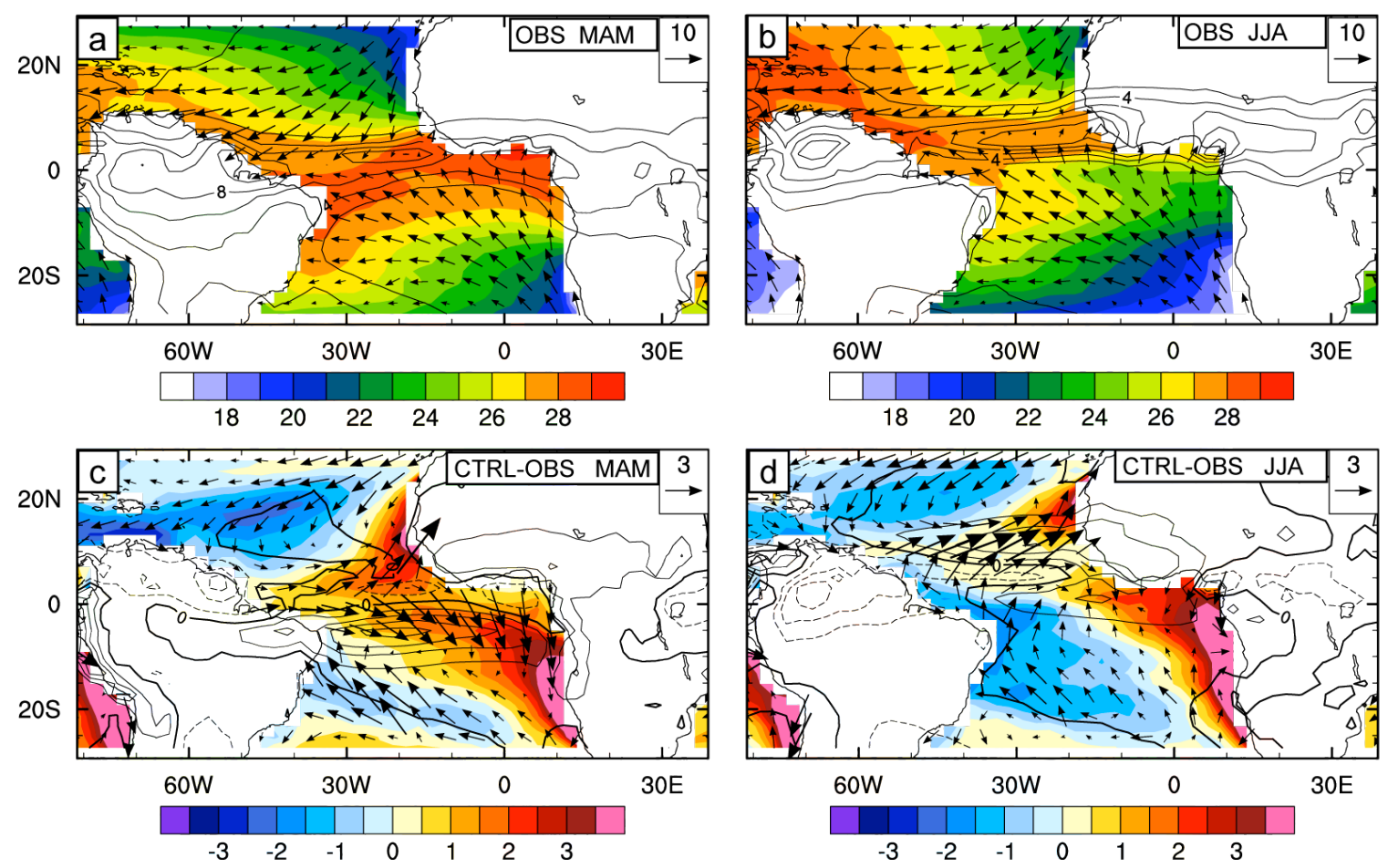

Fig. 1 Climatological mean surface fields in MAM (left panels) and JJA (right panels). The top row (a,b) shows ICOADS SST (shading; ${ }^{\circ} \mathrm{C}$ ), ICOADS surface winds (vectors; reference vector $10 \mathrm{~m} / \mathrm{s}$ ), and CMAP precipitation (contours; interval $1 \mathrm{~mm} / \mathrm{day}$ ). The bottom row (c,d) show biases in CTRL relative to the observations $(\mathrm{a}, \mathrm{b})$. The contour interval for precipitation biases is $2 \mathrm{~mm} /$ day. Dashed contour lines indicate negative values. 


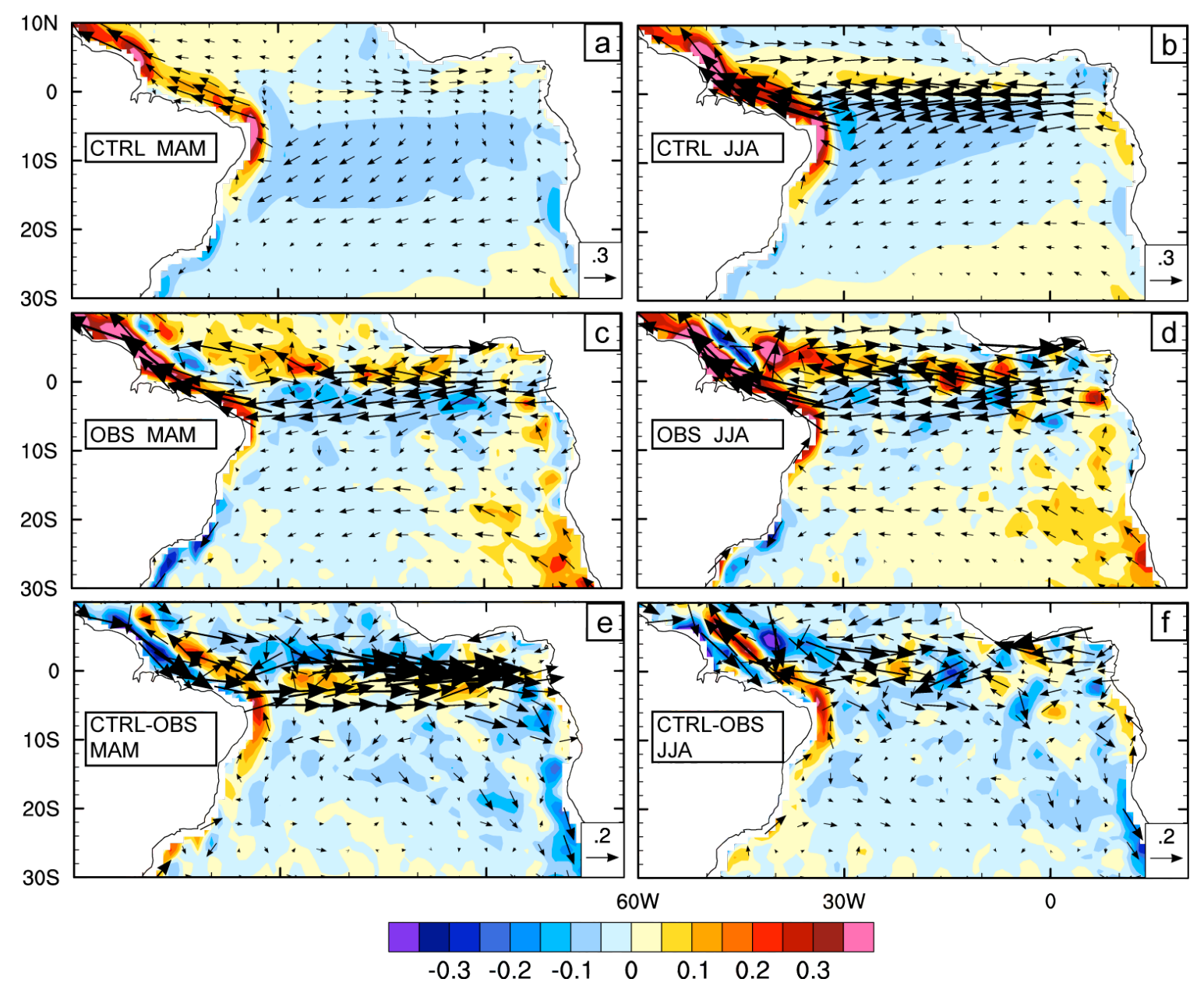

Fig. 2 Climatological mean surface current speed (shading; $\mathrm{m} / \mathrm{s}$ ) and surface current vectors (reference $0.2 \mathrm{~m} / \mathrm{s}$ ) in MAM (left column) and JJA (right column). The top row (a,b) shows CTRL, the middle row $(\mathrm{c}, \mathrm{d})$ AOML drifter observations, and the bottom row $(\mathrm{e}, \mathrm{f})$ the difference between CTRL and the observations. 


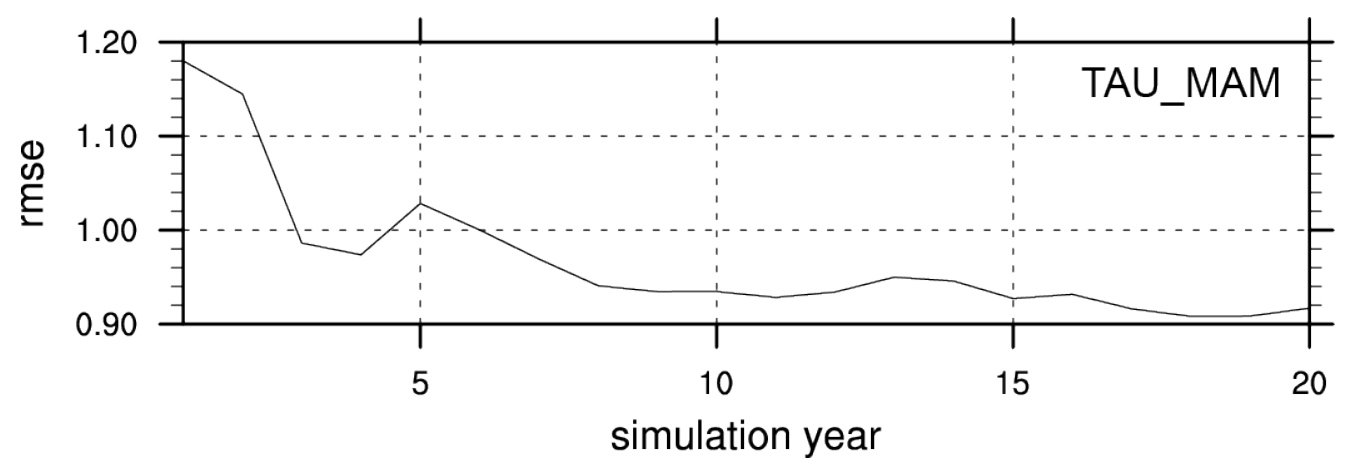

Fig. 3 Cumulative average of the RMSE of equatorial Atlantic SSTs $\left(2^{\circ} S-2^{\circ} \mathrm{N}\right)$ in experiment TAU_MAM relative to CTRL, plotted as a function of accumulation year. Thus, the value for year 5 corresponds to the average over years $1-5$, the value for year 10 corresponds to the average over years $1-10$, etc. 
(a) Observations

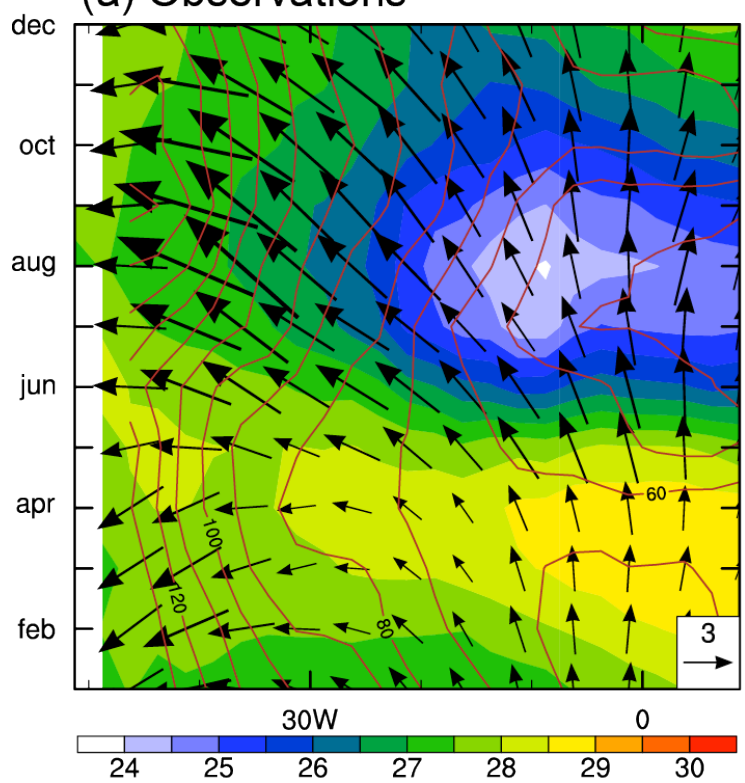

(c) TAU_MAM

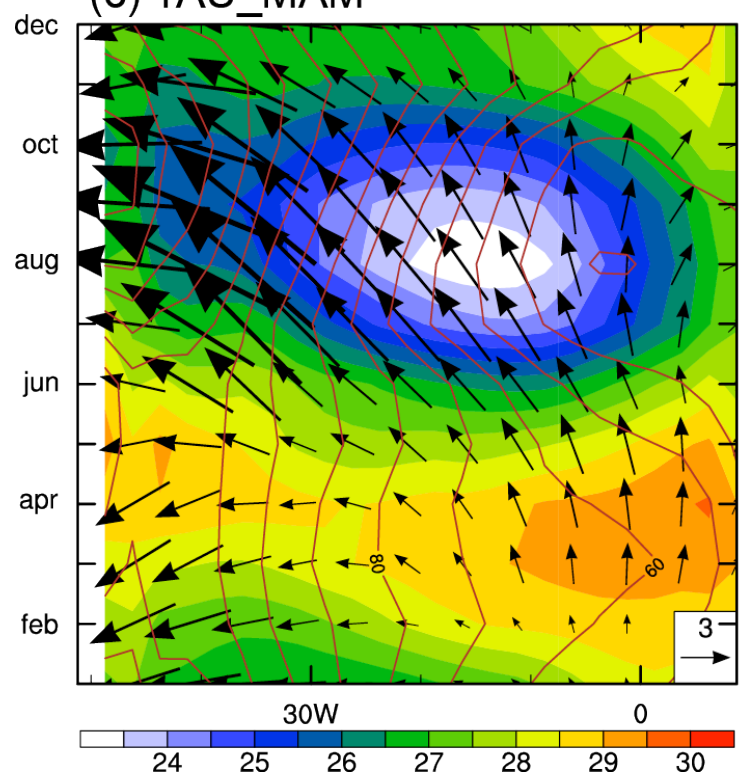

(b) CTRL

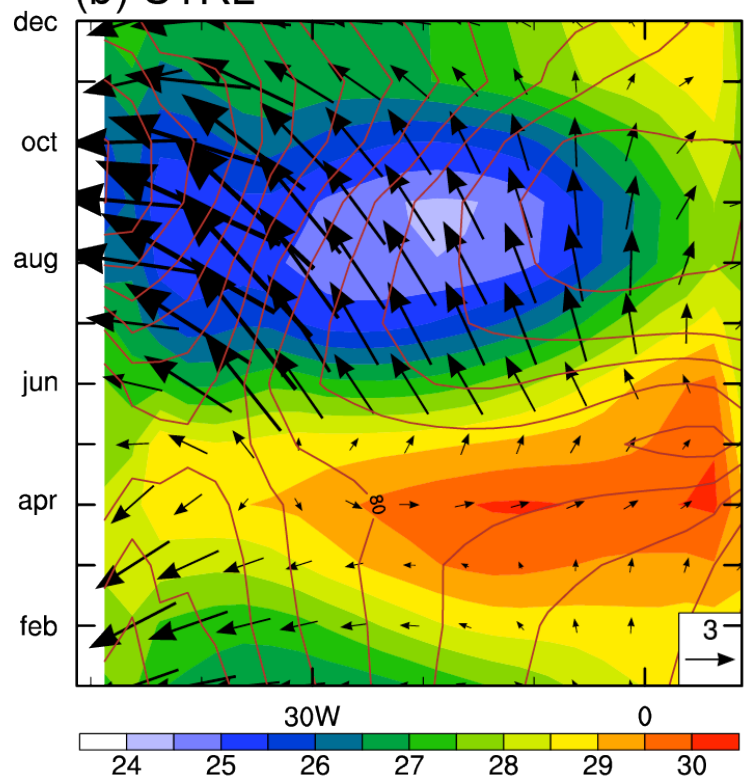

(d) TAU_MAM - CTRL

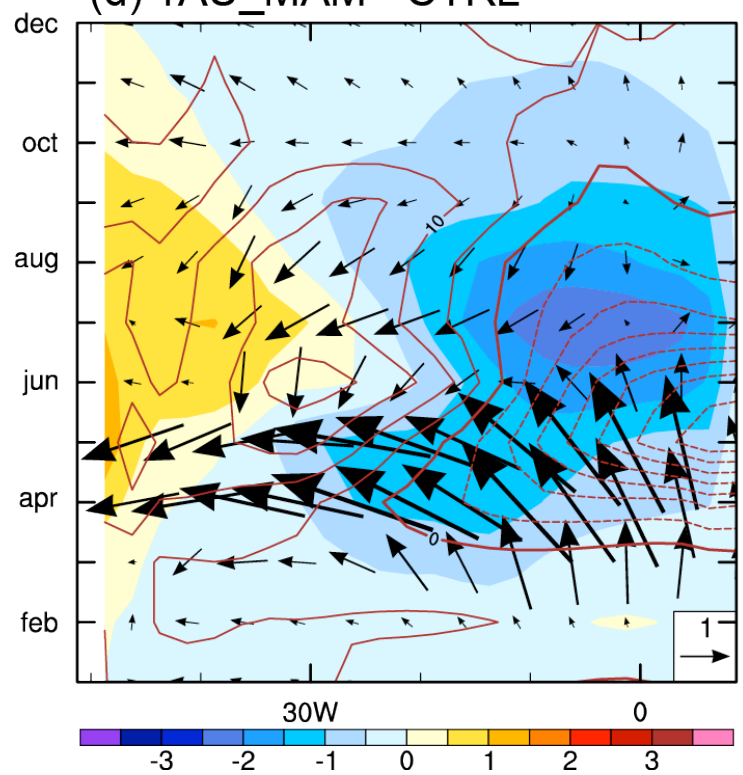

Fig. 4 Longitude-time sections along the equator (averaged from $2^{\circ} \mathrm{S}-2^{\circ} \mathrm{N}$ ) of SST (shading; K), surface wind stress (vectors; $\mathrm{N} \mathrm{m}-2 * 10$ ), and depth of the $20^{\circ} \mathrm{C}$ isotherm (contours; contour interval $5 \mathrm{~m}$ ). The individual panels show (a) observations (ICOADS SST and wind stress, WOA thermocline depth), (b) CTRL (300-year mean), (c) TAU_MAM (20-year mean), and (d) the difference between TAU_MAM and CTRL. 

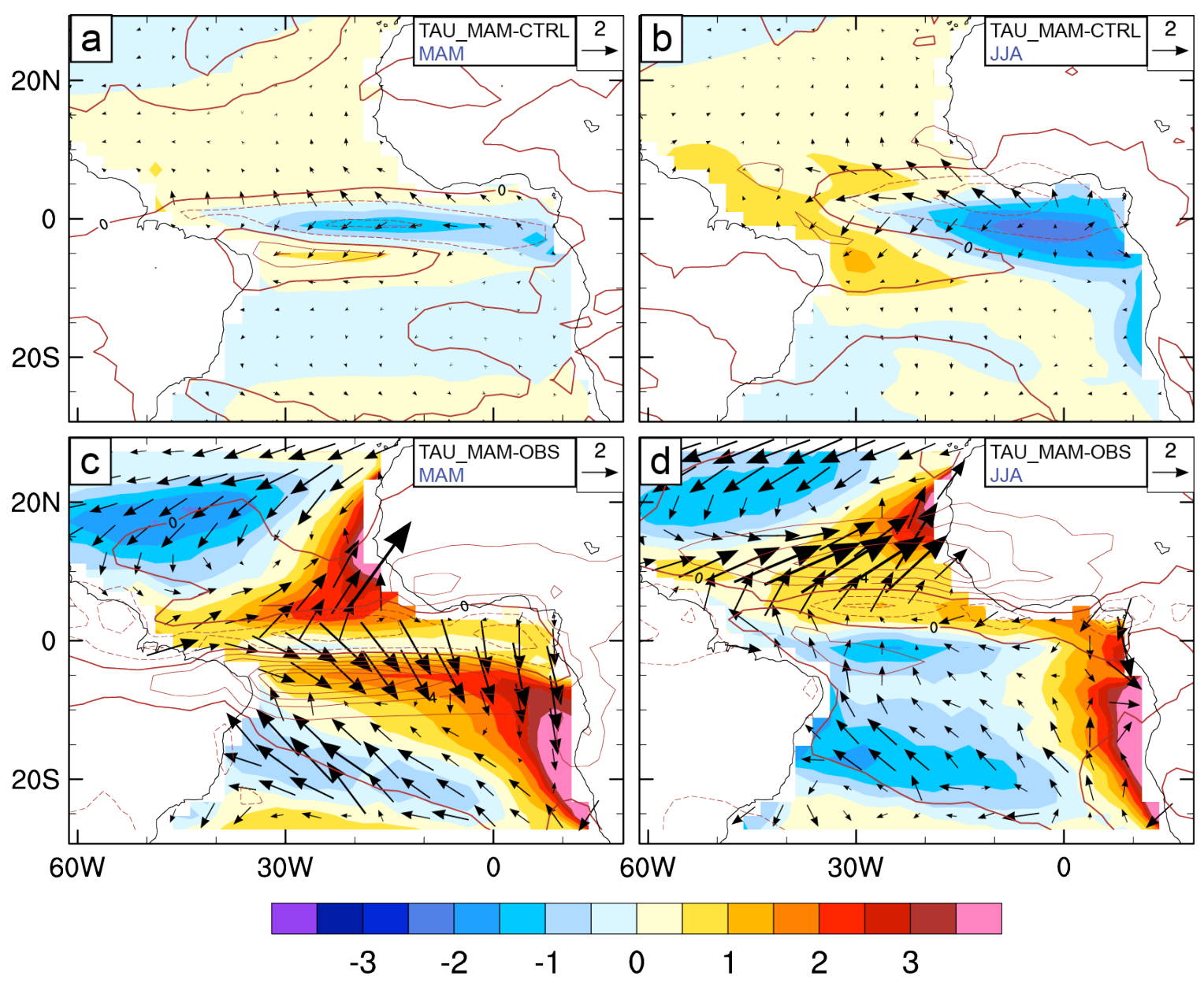

Fig. 5 SST (shading; K), surface wind (vectors; reference vector $3 \mathrm{~m} / \mathrm{s}$ ), and precipitation (contours; contour interval $1 \mathrm{~mm} /$ day) in MAM (left panels) and JJA (right panels) for experiment TAU_MAM, in which equatorial wind stress is prescribed during MAM. The top row shows differences relative to CTRL while the bottom row shows differences relative to ICOADS and CMAP observations. 

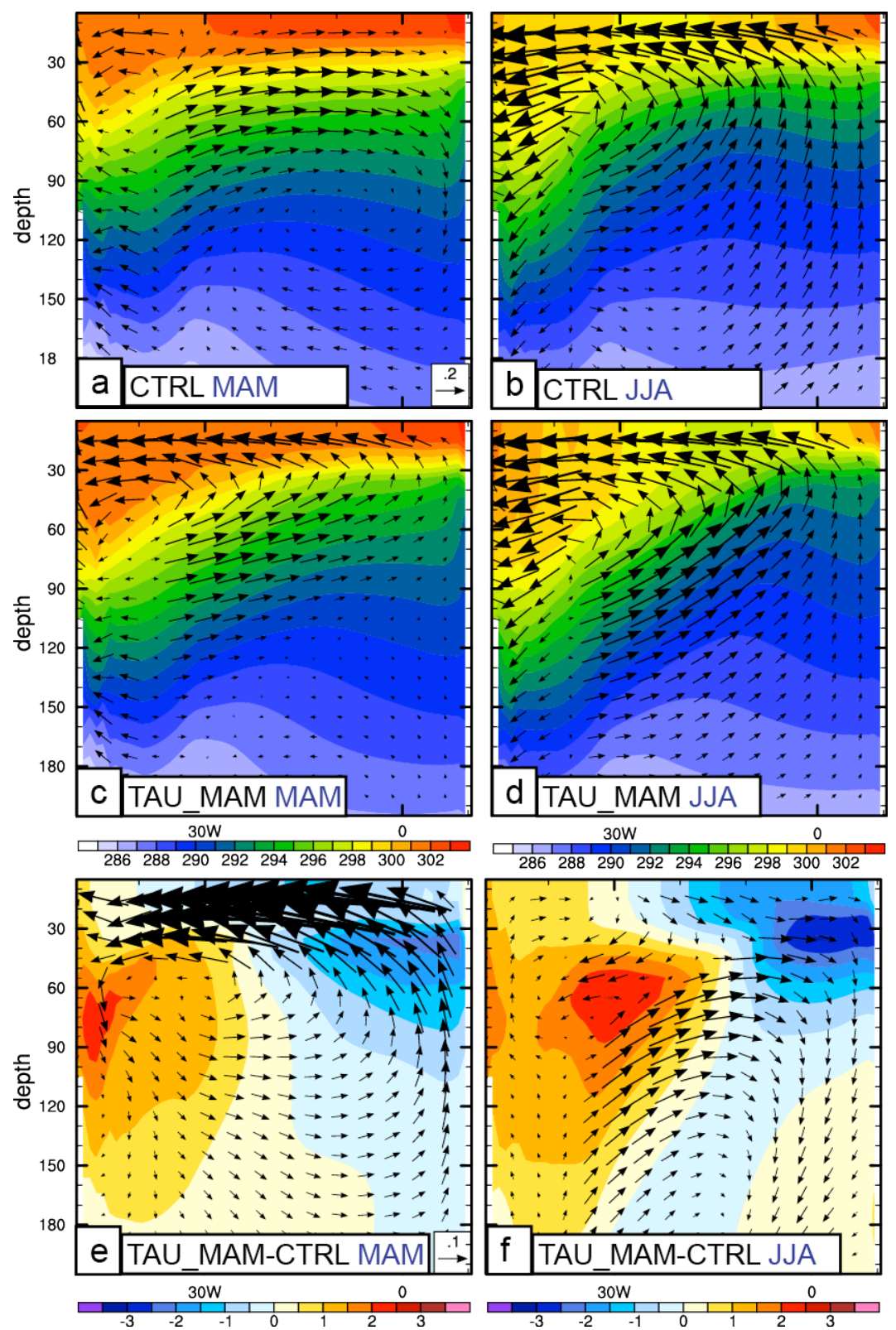

Fig. 6 Longitude-depth sections along the equator (averaged from $2^{\circ} \mathrm{S}-2^{\circ} \mathrm{N}$ ) of potential temperature (shading; K), and zonal and vertical ocean currents (vectors; reference vector $0.1 \mathrm{~m} / \mathrm{s}$; vertical component scaled by 1E3) in MAM (left column) and JJA (right column). The top row (a,b) shows CTRL, the middle row (c,d) shows TAU_MAM (in which equatorial wind stress is prescribed during MAM), and the bottom row $(\mathrm{e}, \mathrm{f})$ shows the difference between the two experiments. 

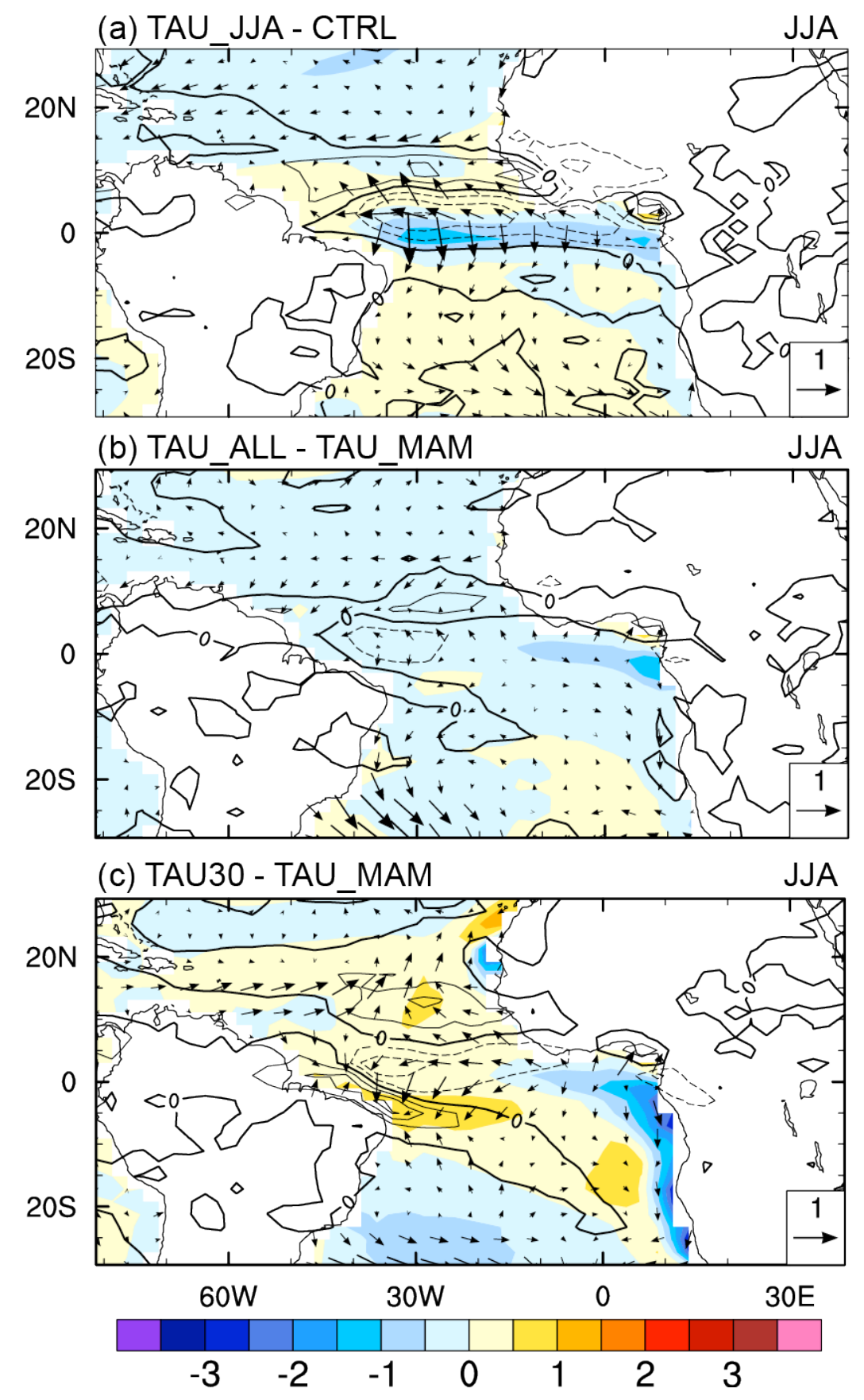

Fig. 7 Difference plots of JJA SST (shading; K), surface winds (vectors; reference vector $2 \mathrm{~m} / \mathrm{s}$ ), and precipitation (contours; contour interval $1 \mathrm{~mm} /$ day). The individual panels show the differences of (a) TAU_JJA relative to CTRL, (b) TAU_ALL relative to TAU_MAM, and (c) TAU30 relative to TAU_MAM. 

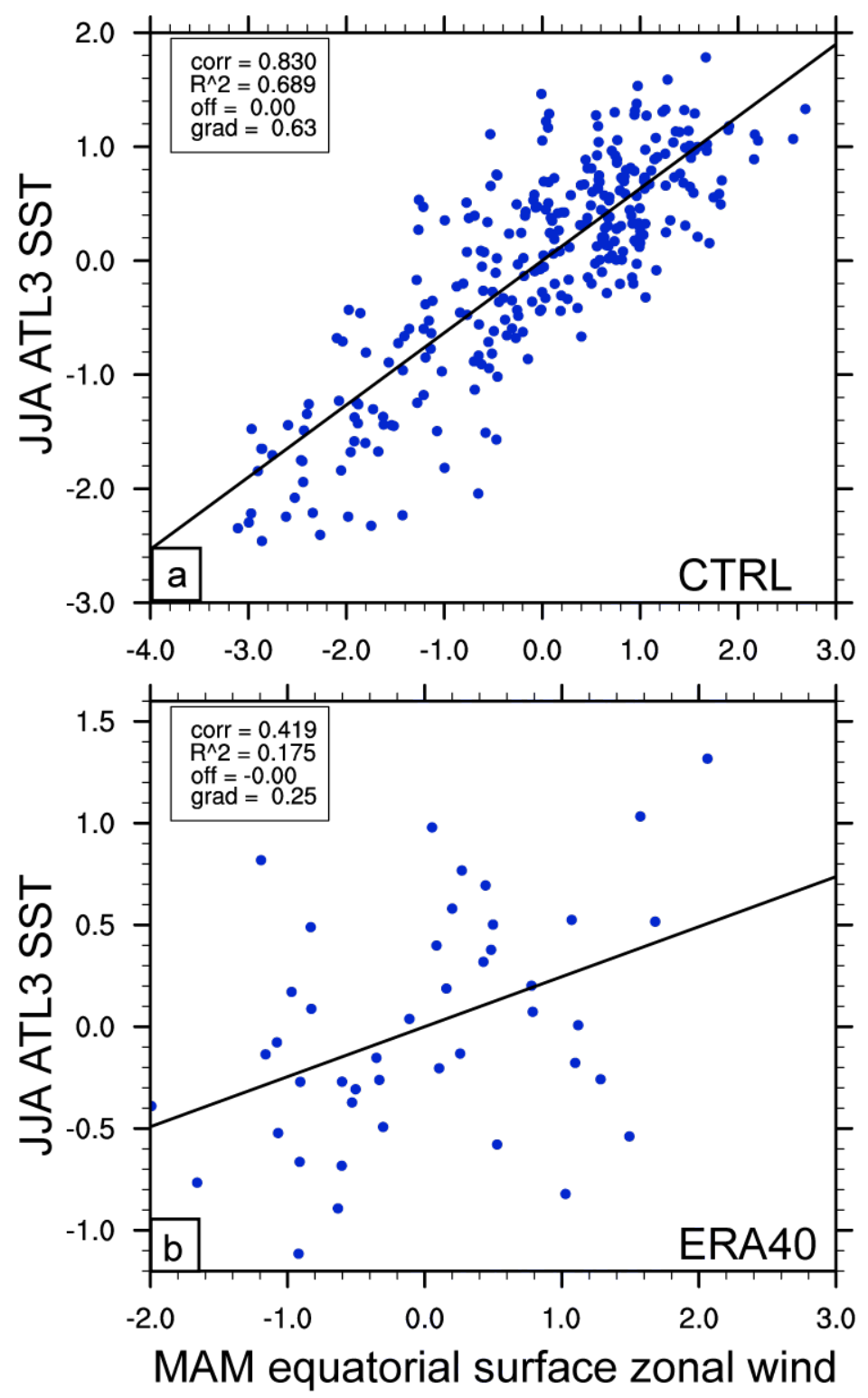

Fig. 8 Scatter plots MAM equatorial surface winds averaged over the area $\left(35^{\circ} \mathrm{W}-25^{\circ} \mathrm{W}, 3^{\circ} \mathrm{S}-\right.$ $3^{\circ} \mathrm{N}$ ) and JJA ATL3 SST for (a) CTRL, and (b) ERA-40 reanalysis. Each dot corresponds to an individual year. 

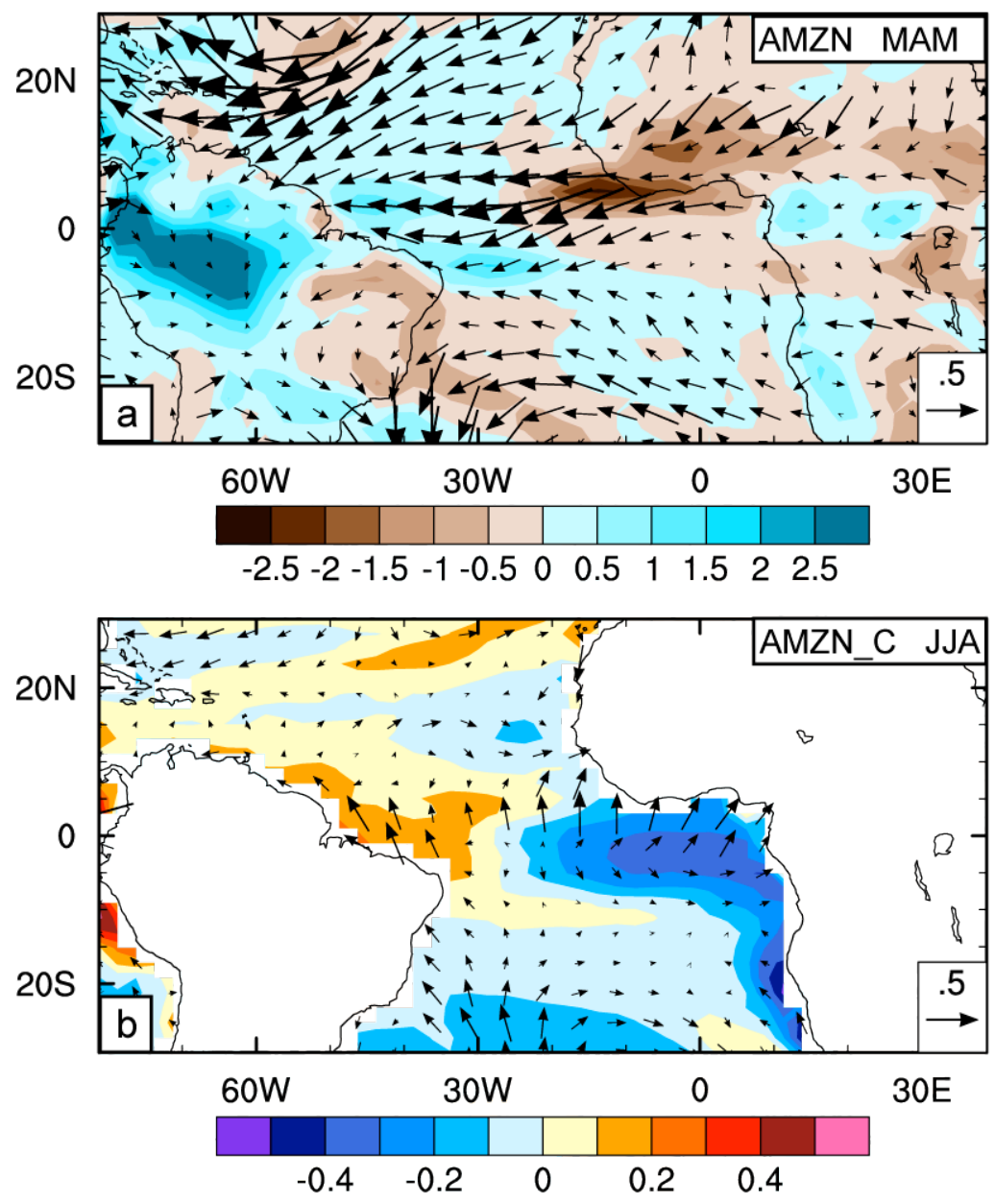

Fig. 9 Difference, relative to CTRL, of surface winds (vectors; reference vector $0.5 \mathrm{~m} / \mathrm{s}$ ) and (a) precipitation (shading; mm/day) and (b) SST (shading; K) for experiments AMZN and AMZN_C, which set surface albedo to 0 in the Amazon region. (a) shows MAM for AMZN, while (b) shows JJA for AMZN_C, the coupled counterpart to AMZN. 

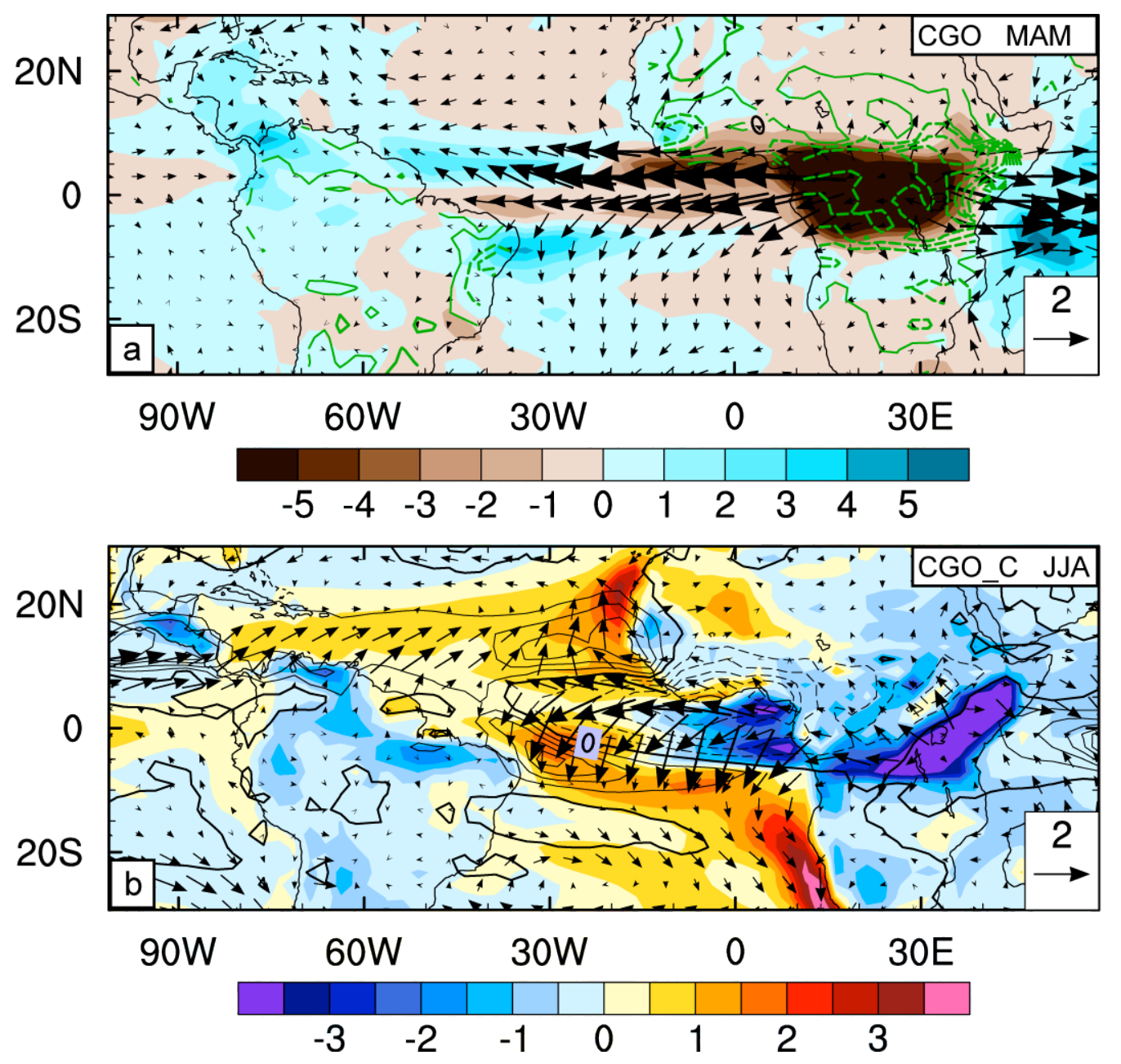

Fig. 10 Difference, relative to CTRL, of surface winds (vectors; reference vector $0.5 \mathrm{~m} / \mathrm{s}$ ) and (a) precipitation (shading; $\mathrm{mm} /$ day) and ground temperature (green contours; interval $1 \mathrm{~K}$ ), and (b) SST (shading; K) and precipitation (black contours; interval $1 \mathrm{~mm} /$ day) for experiments CGO and CGO_C, which set albedo to 0.5 and soil moisture to $200 \mathrm{~kg} / \mathrm{m} 2$ in the Congo basin. (a) shows MAM for CGO, while (b) shows JJA for CGO_C, the coupled counterpart to CGO. 


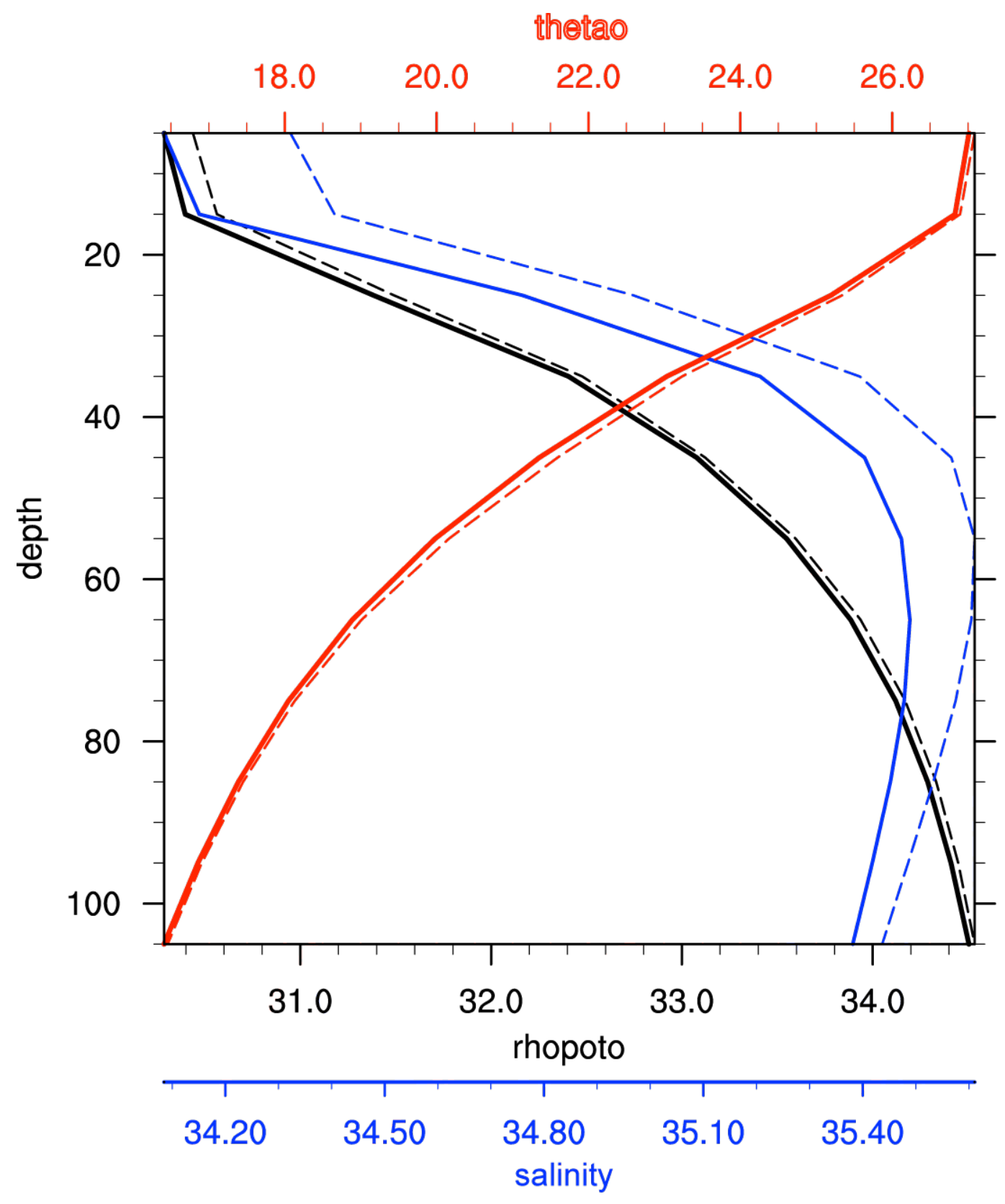

Fig. 11 Vertical profiles of potential temperature (red line), salinity (blue line), and potential density averaged over the ACT region. The solid lines denote CTRL, the dashed lines an experiment in which freshwater flux into the tropical Atlantic is prescribed from observed climatology. 
(a) CTRL-obs

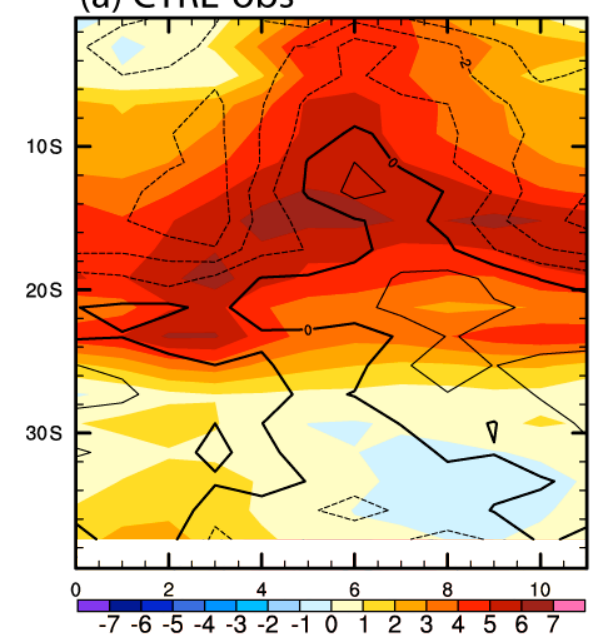

(c) TAU30-CTRL

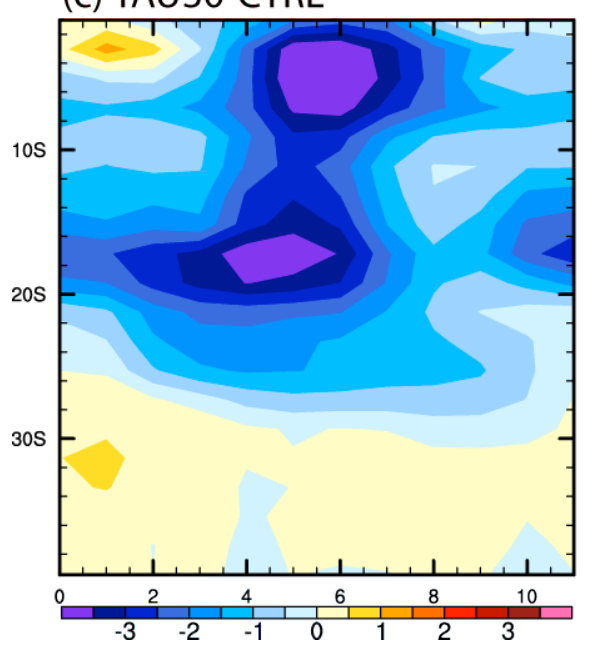

(b) TAU_ALL-CTRL

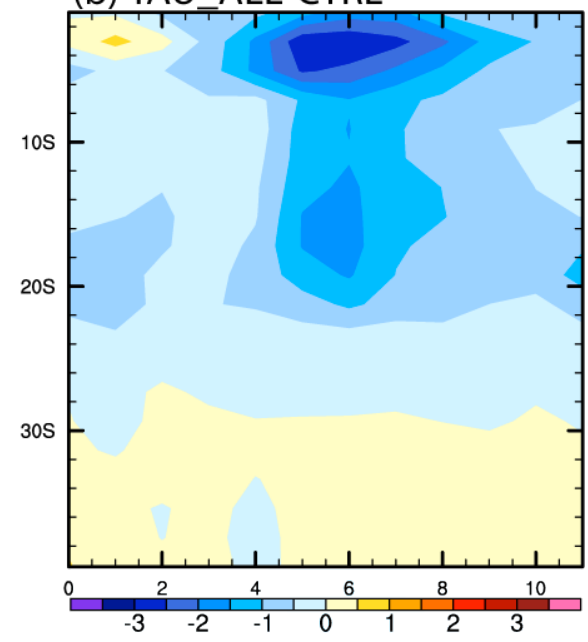

(d) TAU ABA-CTRL

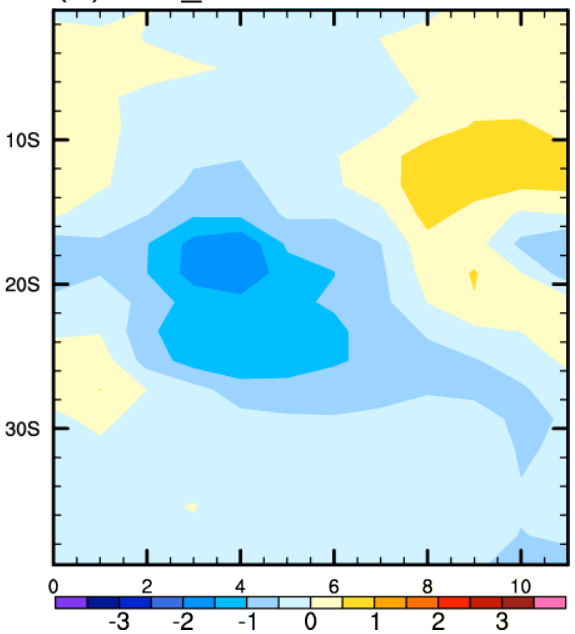

Fig. 12 Latitude-time sections of SST differences (shading; K), averaged between $8^{\circ} \mathrm{E}$ and the African coast. The individual panels show the differences of (a) CTRL and ICOADS, (b) TAU_ALL and CTRL, (c) TAU30 and CTRL, and (d) TAU_ABA and CTRL. The contour lines in (a) denote meridional surface wind differences between CTRL and ICOADS. 

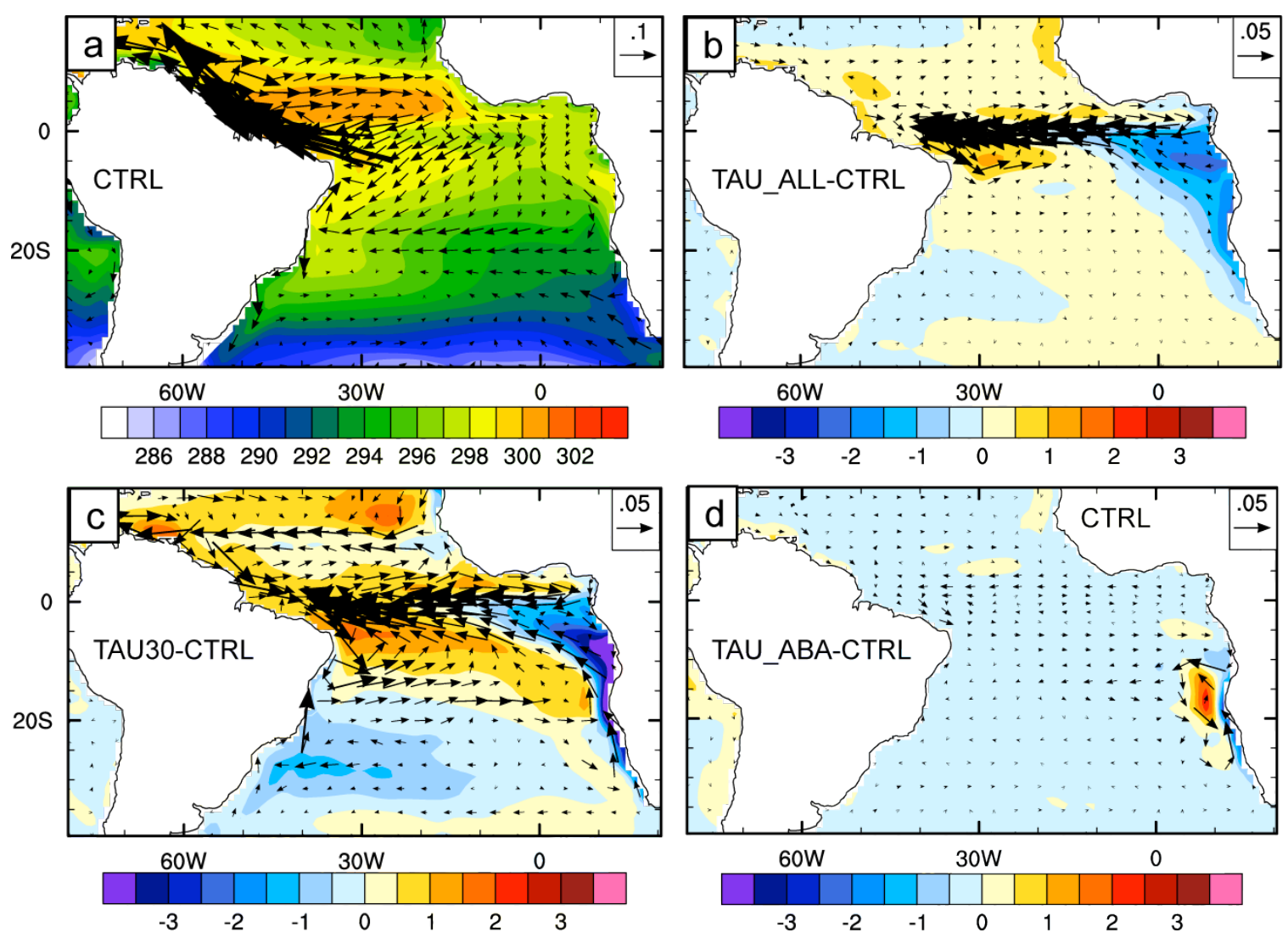

Fig. 13 Horizontal maps of annual mean potential ocean temperature (shading; K), and ocean currents (vectors; reference vector in $\mathrm{m} / \mathrm{s}$ ) averaged between $0-50 \mathrm{~m}$. The individual panels show (a) CTRL, and the differences relative to CTRL for (b) TAU_ALL, (c) TAU30, and (d) TAU_ABA. 